\title{
El sepulcro de Fernando de Antequera y los escultores Pere Oller, Pere Joan y Gil Morlanes, en Poblet
}

\author{
Francesca Español Bertran \\ Universitat de Bracelona \\ Departament d'Història de l'Art \\ Baldiri Reixac $s / \mathrm{n}$ \\ 08028 Barcelona. Spain
}

\section{RESUMEN}

A partir del estudio de una serie de fragmentos escultóricos dispersos por varios museos extranjeros, alguno conservado en Poblet, se plantea una aproximación al sepulcro del rey Fernando de Antequera, obra de Pere Oller, y a las vicisitudes del panteón real a lo largo del siglo Xv. Asimismo, el hallazgo de documentación inédita hasta ahora relativa al coro gótico de Poblet, permite constatar la vinculación al monasterio de una serie de artífices que fueron los responsables del proyecto: Berenguer Cervera, Antoni Gomar y, probablemente, Pere Joan.

Palabras clave:

panteón real de Poblet (s. xv), escultura gótica catalana (s. xv), Pere Oller, Pere Joan, Gil Morlanes, Antoni Gomar, Bartomeu Cervera, coro gótico.

\section{ABSTRACT}

The study of several sculpture fragments, work of Pere Oller, and proceding from Poblet hase helped to make a close connection to the sepulchre of King Ferdinand of Antequera and to the history of the now lost royal family's pantheon along the xvth. century. Also, the discovery of unpublished documents related to the Gothic choir of the monastery reveals and confirms the existence of a series of artists who were responsible for the project, such us: Berenguer Cervera, Antoni Gormar, and possibly Pere Joan

Key words:

royal family pantheon of Poblet (s. Xv), catalan gothic sculpture (s. Xv), Pere Oller, Pere Joan, Gil Morlanes, Antoni Gomar, Bartomeu Cervera, gothic choir. 
$\mathrm{E}$ 114 de marzo de 1416, enfermo en Igualada, el rey Fernando de Antequera se reafirmó en la voluntad de enterrarse en Poblet ${ }^{1}$, ya manifestada en su testamento dictado en Perpiñán el 10 de octubre de 1415. Su inesperada muerte iba a hacerlo realidad al mes siguiente. $\mathrm{Fa}$ lleció en ese lugar el 2 de abril de 1416, siendo trasladado su cadáver al monasterio para celebrar las exequias $^{2}$. Nada hace suponer que tuviera tiempo de preparar su monumento funerario en vida $y$, por este motivo, la carta que dirigió el 21 de enero de 1417 su hijo Alfonso el Magnánimo al abad respecto al escultor Pere Oller, se ha venido interpretando como fecha inicial del proyecto ${ }^{3}$. No sólo están a su favor los términos de la misiva, puesto que se envía al maestro a Poblet para "veure regoneixer e fer les coses necessaries per lo monument o tomba del cors del Senyor Rey», sino un hecho incontrovertible: la serie de restos escultóricos procedentes del cenobio de inequívoca temática funeraria, cuyos rasgos estilísticos apuntan al arte de este artífice. Se trata de un grupo de plorantes y una escena en relieve, repartidos en la actualidad entre Poblet y varios museos extranjeros, que han sido objeto de atención por parte de los historiadores en distintos momentos ${ }^{4} \mathrm{y}$ de los que nos vamos a ocupar en las páginas que siguen. El hallazgo de nuevos fragmentos que pueden proceder de este mausoleo permite afrontar una reconstrucción hipotética del mismo y, por otro lado, la atribución reciente del elemento más emblemático del sepulcro al círculo del escultor Pere Joan $^{5}$, invita a meditar sobre la viabilidad de esa atribución. Todo esto, junto con una posible explicación de lo que pudo suceder en la obra del panteón real pobletano a lo largo del siglo Xv, va a ser el horizonte de nuestro trabajo.

\section{Dispersión de los elementos del sepulcro}

Sin embargo, antes de llegar a ese punto que nos va a permitir especular sobre la tipología, la disposición y la autoría del monumento que la crítica historiográfica identifica como perteneciente al rey Fernando de Antequera, se hace necesario reconstruir, en la medida de lo posible, la historia de esos elementos que lo integraban y que hoy constituyen un ejemplo elocuente de lo que deparó a los monumentos españoles la exclaustración y el posterior decreto de Desamortización de los bienes eclesiásticos (1836). Como ocurrió en muchos otros casos, el monasterio de Poblet quedó abandonado y, debido a ello, el edificio y todo el arte mueble que custodiaba en su interior, a merced de curiosos y amantes de las antigüedades, durante años. En el caso de los sepulcros reales emplazados sobre sendos arcos en el área inmediata al presbiterio, la expoliación de su escultura fue sistemática. Todo ello, a pesar de los esfuerzos de la Comisión Provincial de Monumentos de Tarragona por preservar el monumento del vandalismo de los visitantes, o de la codicia de los anticuarios ${ }^{6}$. Pi y Margall escribía por entonces:

Vinieron después de los destructores los artistas, y por un mal entendido amor al arte hicieron desaparecer los fragmentos de los sepulcros que debían darnos ahora una idea aunque imperfecta de lo que antes fueron ${ }^{7}$.

Uno de los destinatarios de diversos fragmentos escultóricos de los sepulcros de Poblet fue el abogado, historiador y coleccionista barcelonés
1. Para las disposiciones testamentarias: I.I. MACDONALD, Don Fernando de Antequera, Oxford, 1948. Publica el documento posterior: F. Vendrell de Millas, «Tres nous documents sobre les relacions entre el rei Ferran I d'Aragó i el monestir de Poblet», en: Miscellanea Populetana, Abadia de Poblet, 1966, p. 351352, doc. 2.

2. «Dijous â 2 de Abril, cerca mitg die en Igualada morí lo Rey Don Ferrando, y fou sepultat â Poblet y per sa malaltia la Ciutat li trameté â Joan Fivaller Conseller segon, y altros Missatgers per visitarlo, â 18 de Mars, y tornaren â 30 de Maig venint ab lo Rey Namfos son fill. Lo Aniversari en Barcelona se feu â 24 de Abril, foren fetas gramallas de trellís per als Consellers, y alguns servidors de la Ciutat [...] lo dit Namfos volgué que lo Conseller lo Acompanyás â Poblet, portan allá lo cors del Rey mort, y la ciutat hi tramaté un Pali de or, y cent brandons de cera, y la cera costá [...], los dos Imperials costaren [...],» (RubRiQues De BRUNiQUer, Ceremonial dels Magnifichs Consellers y Regiment de la Ciutat de Barcelona, vol. I, Barcelona, 1912, p. 329). «A 18 de març de 1416 partiren los honorables en Joan Fivaller Conseller, y altros Missatgers per anar á visitar al Sor. Rey en Igualada hont estava malalt y mori dit Rey â 2 de Abril, fou soterrat â Poblet y tornaren los dits Missatgers â 30 de Maig, venint ab lo Sor. Rey Namfos qui era fill del Rey mort» (ibídem, vol. II, Barcelona, 1913, p. 179).

3. Dio noticia del documento: Conde de la Viñaza, Adiciones al Diccionario histórico de Juan Agustín Cean Bermúdez, vol. I, Madrid, 1889, p. 110-111. Posteriormente, lo han publicado íntegro: R. DEL ARCo, Sepulcros 
Joan Cortada i Sala (1805-1868) $)^{8}$, quien, a la curiosidad por los testimonios del pasado, unía su condición de director del Museo de Antigüedades, fundado por la Real Academia de Buenas Letras de Barcelona. Habiendo transcurrido menos de diez años desde la Desamortización, nuestro personaje, según informa la Guía cicerone de Barcelona de Antoni de Bofarull ${ }^{9}$, ya exhibía en su casa, situada en la calle de la Merced número 28, segundo piso ${ }^{10}$, «un alto relieve de alabastro del siglo XV que representa tres personajes montados, uno de los cuales lleva corona ducal» ${ }^{11}$, Nada se nos dice de la procedencia de esta pieza, pero, como ya invocamos en su momento ${ }^{12}$ y veremos más adelante, se trataba del fragmento más notable relacionado con el sepulcro de Poblet que estudiamos. Cortada poseía otras piezas de ese origen, en lo que él mismo catalogaba como su museo particular, pero que abría a los curiosos según se deduce de la atención que le prestan diversas guías de la ciudad de Barcelona de mediados del XIX ${ }^{13}$. Así lo apunta lacónicamente la guía ya citada de Antoni de Bofarull: «varios restos de Poblet» ${ }^{14}$.

La Comisión Provincial de Monumentos de Tarragona, informada de la existencia de esos fragmentos, escribió a Cortada el 30 de junio de $1846^{15}$. Le encarecía a no desprenderse de un relieve -que la Comisión identifica como procedente de las cámaras sepulcrales de los Cardona ${ }^{16}$ pero que todo hace pensar era el que estamos analizando-, procedente del sepulcro real. Nos lleva a esta conclusión el valor que se reconoció a este fragmento

de la casa Real de Aragón, Madrid, 1945, p. 360. F. MARËS, Las tumbas reales de los monarcas de Cataluña y Aragón del monasterio de Santa María de Poblet. Barcelona, 1952, p. 243, doc. 23. Aluden a él: A. Duran i SANPERE, Els retaules de pedra, vol. II, Barcelona, 1934, p. 29 , ídem, «Les escultures de Poblet a Poblet», Butlletí dels Museus d'Art de Barcelona, IV (1934), p. 157-160. Trabajo publicado de nuevo en el Butlletí Arqueològic de Tarragona, (1929-1934), p. 360-363. A Altisent, Historia de Poblet, Abadia de Poblet, 1974, p. 294 295. Transcribimos parcialmente el documento en la nota 105.

4. Presentamos la bibliografía específica, al introducir cada una de estas piezas a lo largo de las páginas que siguen.

5. Sobre esta problemática específica, véase más adelante el cuarto apartado de nuestro estudio.

6. Sobre la actuación de esta comisión: J. SERRA I VILARÓ, $\mathrm{La}$ Comisión de monumentos históricos y artísticos de la provincia de Tarragona ante las ruinas del mo. nasterio de Poblet, Tarragona, 1946. a lo largo del siglo XIX. Los términos de la carta son tan extremadamente prudentes y diplomáticos, que cabe la sospecha, al leerla, que los miembros de la Comisión de monumentos recelaran del comportamiento de Cortada en la obtención de la pieza:

Sabedora esta Comisión que V.S. posee un fragmento o relieve procedente del panteón del duque de Cardona que existía en el mencionado Monasterio de Poblet y enterada, asimismo, del laudable celo de V.S. por los monumentos que atestiguan las antiguas glorias de nuestro país, se dirige a V.S. para recomendarle encarecidamente la conservación del citado fragmento y cuantos más acaso posea y en lo sucesivo adquiera de igual procedencia...

La respuesta de Joan Cortada no se hizo esperar. Fechada el 11 de julio de 1846, resultan muy interesantes los términos que usa para presentarse a sí mismo como amante de las antigüedades y prócer comprometido en su salvaguarda ${ }^{17}$, pero el tono de la carta no está exento de una cierta arrogancia. Sospechamos que pudo obedecer a su incomodidad ante la carta de la Comisión. Aunque en su respuesta alude al regalo de un amigo suyo, no hay que olvidar que los nexos de Cortada con Tarragona, familiares, en origen, alcanzaron con el tiempo lo político ${ }^{18}$, y que disfrutar de una situación como ésta durante el siglo XIX conllevaba muchas veces alguna suerte de clientelismo. Al fi-
7. El texto es unos diez o doce años posterior a la Desamortización (cf. F. Parcerisa, F. Pi I Margall, Recuerdos y Bellezas de España. Cataluña, vol. II, Barcelona, 1848, p. 292). Indudablemente, la referencia a los artistas no puede ser gratuita y se nos ocurre un posible nombre: el del pintor Claudio Lorenzale que sabemos coleccionó fragmentos de Poblet, heredados luego por Elies Rogent. Véase, al respecto: E. Toda, La destrucció de Poblet 1836-1900, Sant Boi de Llobregat, 1935 , p. 241.

8. Sobre el personaje, véase el estudio reciente de: A. GHANIME, Joan Cortada: Catalunya $i$ els catalans al segle XIX, Barcelona, 1995.

9. A. De Bofarull, Guía cicerone, Barcelona, 1847, p. 144.

10. En la nueva edición de la Guía de Antonio de Bofarull, que apareció en 1855 y donde el capítulo sobre el Museo Cortada ocupa las páginas 103-109, el Museo se localiza en un lugar distinto al inicial. Quizá en el origen de este cambio esté el matrimonio de Cortada en 1851, que estableció su residencia en Sant Gervasi de Cassoles (A. GHANimE, op. cit., p.
93). El Museo consta entonces en la Riera de San Juan número 31, segundo piso. Advertimos que las citas de la Guía de Bofarull las haremos siempre a partir de la primera edición. Otras referencias sobre la colección en: A. García i SASTre, Els Museus d'Art de Barcelona: Antecedents, gènesi i desenvolupament fins l'any 1915, Barcelona, 1997, p. 235-236.

\section{A. DE BofArull, op. cit., p. 144.}

12. Dimos a conocer este dato en relación con el relieve pobletano, en: F. EsPañol, «Plorantes del sepulcre de Ferran d'Antequera», en: Catalunya Medieval, catálogo de exposición, Barcelona, 1992, p. 240. Lo toma de nosotros: M. R. MANOTE, «Correr les armes, cerimònia dels funerals dels reis d'Aragó, representada en un relleu del monestir de Santa Maria de Poblet", Lambard, VIII (1993-1994) (1995), p. 93-94.

13. Otra guía de la ciudad habla de él. Lo remarcó: M.R. MANOTE, «Un relleu català al Museu del Louvre», Daedalus, I (1979), p. 25. Se trata de la de M. SAuri y J. Matas, Manual histórico-topográfico estadistico y administrati- vo ó sea Guia general de Barcelona, Barcelona, 1849 , p. 177-178. «Aunque reciente y escaso de objetos, [el Museo Cortada] llama la atención y merece estudiarse [...] [Hay en él] varios fragmentos de alabastro y marmol del siglo xv perfectamente conservados [...] cuyo señor con la amabilidad que le distingue, se esmera en enseñarlo minuciosamente á las personas que desean verlo».

14. A. De Bofarull, op. cit., p. 144.

15. J. SERra i Vilaró, op. cit., p. 143.

16. La noticia de esta carta, alusiva al coleccionismo de Cortada de diversos fragmentos pobletanos, la da a conocer M. R. MANOTE, («Correr les armes», p. 93-94), aunque no la relaciona directamente con el relieve que tratamos. Sin embargo, es más que probable que se aluda a él, considerando su emplazamiento primitivo. Recordemos que el panteón de los Cardona se hallaba localizado en la zona baja de los arcos reales y que era fácil confundir este lugar con la zona inmediatamente superior. La construcción de las cámaras sepulcrales de los Cardona supuso un cambio notable en la apariencia externa de los arcos reales, puesto que se cegaron, lo que reflejan claramente las litografías y los grabados realizados durante el siglo XIX para los Recuerdos y Bellezas de Espa$\tilde{n} a$ o para el Voyage Pittoresque, de Alexandre Laborde, de los que tratamos más adelante. Sobre la obra de las cámaras sepulcrales de los Cardona: C. Martinell, «La Casa de Cardona y sus obras en Poblet», Estudios históricos y documentos de los archivos de protocolos, II (1950), p. 53-119. J. M. Madurell Marimon, «La obra de las cámaras sepulcrales de Poblet y la Casa de Cardona», Estudios históricos y documentos de los archivos de protocolos, III (1955), p. 245-266.

17. J. Serra i Vilaró, op. cit., p. 143-144.

18. A. Ghanime, op. cit., p. 2930 , 83. Joan Cortada, no sólo vivió en Tarragona durante su infancia y veraneó en la ciudad al menos el año 1848 (ibídem, p. 62), sino que llegó a ser elegido diputado a Cortes por esa circunscripción en 1843. 


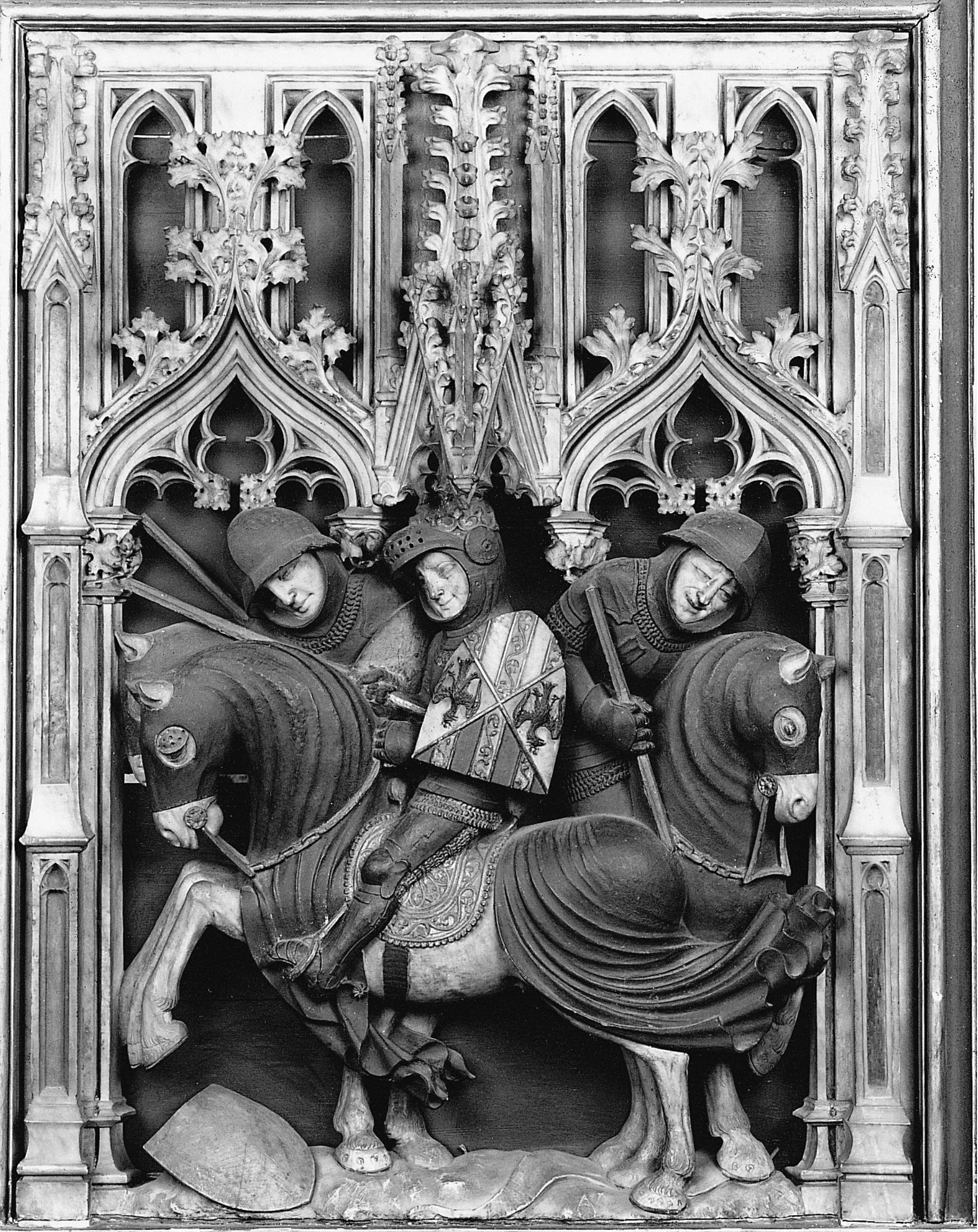


nal, el relieve, que en honor a la verdad no había sido reclamado, quedó en manos de la familia Cortada hasta bastantes años despues (figura 1).

Allí debió verlo Pau Milà i Fontanals. Un dibujo a lápiz y coloreado de 29 x 22,5 cm, que se le atribuye, perteneciente a los fondos de la Reial Acadèmia Catalana de Belles Arts de Sant Jordi de Barcelona, lo confirma (figura 2). En su ángulo inferior izquierdo consta la siguiente anotación: «Mo(nasterio) de Poblet de los Panteones Reales», y en el derecho: «Museo Cortada» ${ }^{19}$. La fidelidad de Milà al original es notoria. El dibujo, expuesto públicamente por vez primera el año 1975, en Barcelona, permitió constatar su dependencia respecto a un relieve que se custodiaba en el museo del Louvre de París desde 1911, donde había ingresado como parte del legado Isaac Camondo ${ }^{20}$. Las escuetas anotaciones del dibujo corregían, además, el falso origen valenciano que en algún momento se había atribuido a la pieza, e, incluso, el carácter de la obra: no se trataba del fragmento de un retablo, como se creía, sino de un relieve funerario ${ }^{21}$.

La escena que se desarrolla bajo una rica arquería corrida gótica, tiene este signo. Muestra a tres jinetes montados sobre sus cabalgaduras, ricamente ajaezadas con gualdrapas de color oscuro. Los caballeros visten el arnés blanco que fue común en Cataluña en los años iniciales del siglo $\mathrm{Xv}^{22}$, y sostienen lanzas. El que está situado en primer término luce sobre su bacinete lo que parece una cime$\mathrm{ra}^{23}$ y se protege con un escudo en el que campean las armas del reino de Sicilia ${ }^{24}$. La disposición invertida es el rasgo más singular de éste último. Corresponde a lo que en la época se denomina «armas a la funerala». Se trata de una particularidad que, al igual que el hábito de cortar las colas de los caballos, aunque en este caso no sea perceptible porque quedan ocultas, era indicativo de duelo ${ }^{25}$. El relieve muestra, pues, un episodio perfectamente acorde con el ámbito del que sabemos procede ${ }^{26}$.

Corresponde a una celebración funerario-caballeresca documentada en la Corona de Aragón, al menos desde el siglo XIII, denominada «correr les armes», de la que nos hablan las fuentes contemporáneas y de la que restan, como veremos, significativos testimonios iconográficos.

No se sabe donde se realizó el dibujo, pero podemos sospechar que fue en el propio Museo Cortada. Revisando el fondo Milà i Fontanals de la Academia, he localizado un nuevo dibujo, sin identificar hasta ahora ${ }^{27}$, que parece proceder del mismo sepulcro que el relieve (figura 3). Aunque no es la única posibilidad ${ }^{28}$, podría corresponder a ese indefinido «varios restos de Poblet» que cita la guía de Antonio de Bofarull en su registro de la colección Cortada. Si bien Milà hizo apuntes de varios túmulos de la catedral de Barcelona con plorantes en sus frontales, he comprobado si la figura coincide con alguno de ellos - el del obispo

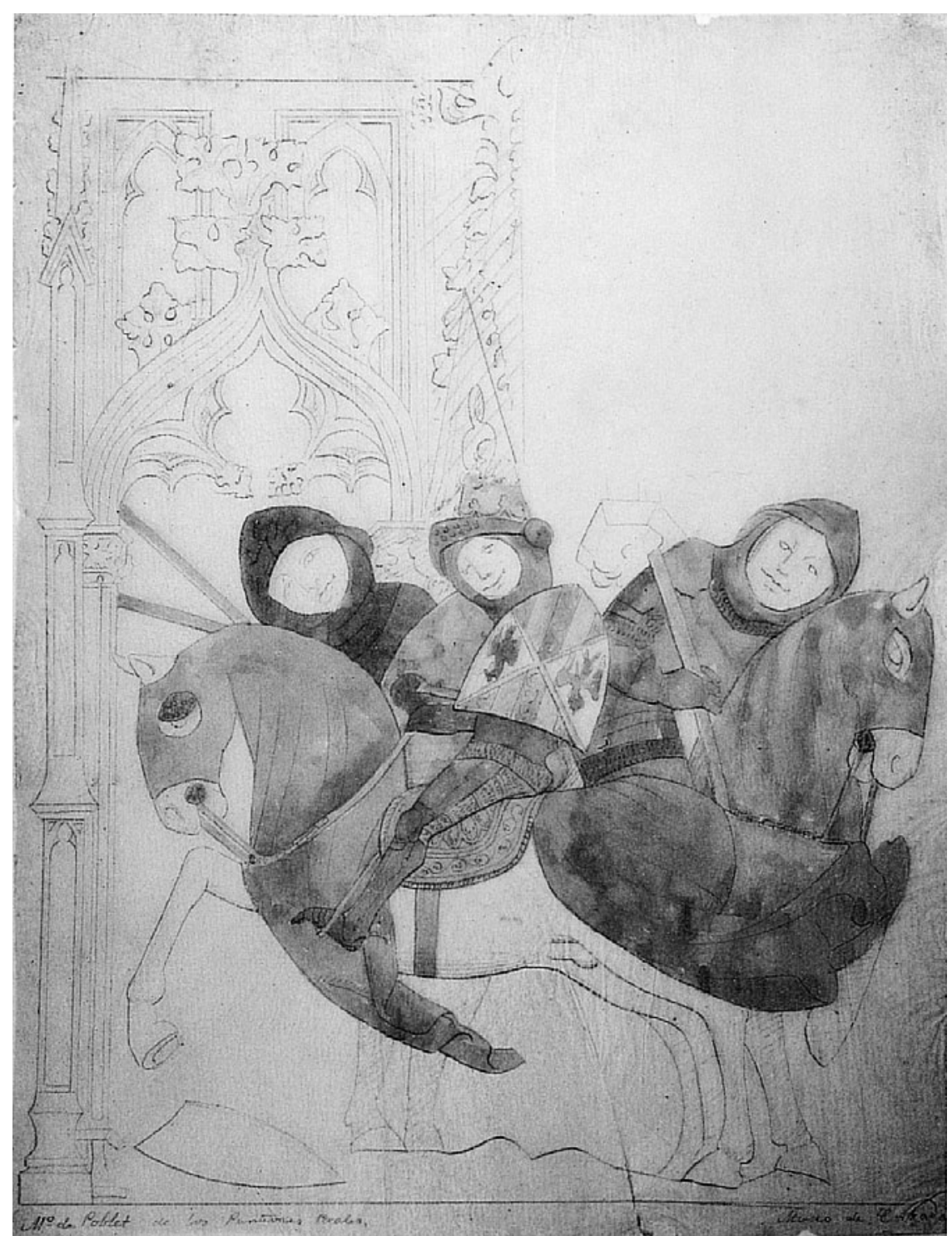

Figura 2.

Mo(nasterio) de Poblet, de los Panteones Reales. Museo Cortada.

Dibujo de Pau Milà i Fontanals. Barcelona, Reial Acadèmia Catalana de Belles Arts de Sant Jordi.

19. Barcelona, Reial Academia de Belles Arts de Sant Jordi, Fondo de dibujos Pau Milà i Fontanals. Número de inventario $1912 \mathrm{D}$. Agradezco a Victoria Durà, la conservadora de este fondo, las facilidades para su consulta.

20. París, Museo del Louvre, número de inventario RF 1521 (mide: $64 \times 48 \times 13 \mathrm{~cm}$ ). M. R. Manote dedicó en 1979 un trabajo a este relieve, dando a conocer estas noticias ( $U n$ relleu català..., p. 24-25). En 1995, con otro título (Cf. Correr les armes...), lo republicó de nuevo sin cambios sustanciales respecto al redactado del primer texto, salvo en su aparato crítico y en la parte final del estudio, que fue reelaborada y ampliada.

21. La bibliografía de la pieza en:
M.R. Manote, Un rellen català..., p. 22-23.

22. M. DE Riquer, L'arnés del cavaller. Armes $i$ armadures catalanes, Barcelona, 1968, p. 93 y s.

23. Ibídem, p. 119 y fig. 185-187

24. Aparecen en flangé los palos de Aragón y las águilas sicilianas. Sobre estas armas: M. DE RIQUER, Heràldica catalana. Des de l'any 1150 al 1550, vol. I, Barcelona, 1983 , p. 312 y s.

25. Sobre estos aspectos en el contexto catalán medieval, F. ESPAÑOI BERTRAN, La escultura gótica funeraria en Cataluña, tesis doctoral, Universidad de Barcelona 1987, vol. I, capítulo 1, p. 1-61. Véase tambien el apartado número $5 \mathrm{del}$ presente trabajo.
26. Como ya lo señalaron aquéllos que se refirieron antiguamente a esta pieza (cf. los trabajos en las notas 33, 34 y 35). Más recientemente: M.R. MANOTE, Un relleu català..

27. Barcelona, Reial Academia de Belles Arts de Sant Jordi. Fondo dibujos de Pau Milà i Fontanals. Número de inventario $2362 \mathrm{D}$.

28. Pau Milà i Fontanals, por la amistad que les unía, tambien pudo tener acceso a los plorantes pobletanos que poseía Claudio Lorenzale (véase la nota 7). Aunque ignoramos cuáles eran y de qué sepulcro procedían, por el momento es una posibilidad no descartable. 
pulcro. Recordemos la presencia en el Museo Cortada, junto al valioso relieve, de los varios restos de Poblet registrados por la guía de Bofarull. Algunas de esas figuras, repartidas hoy entre Poblet y varios museos extranjeros, irrumpen en el mercado anticuario por entonces, y especular con la posibilidad de que fueran los familiares del coleccionista quienes los pusieron a la venta — al menos alguna de ellas- es más que factible. Volveremos a retomar esta cuestión. Por lo que respecta al del relieve del «correr les armes» tres fuentes nos hablan de su venta en estos términos.

La primera corresponde a la noticia que se insertó en el primer volumen de la Revista de la Asociación Artístico Arqueológica Barcelonesa: «Recientemente ha pasado a enriquecer una colección de Antigüedades del extranjero, un precioso alto relieve marmóreo, procedente, al parecer, de la parte delantera de un sepulcro de Poblet, en el cual hay esculpidos varios caballeros y soldados del siglo xv campeando en los escudos de aquellos la divisa o blasón partido de la Casa Real de Aragón y Sicilia. Dicha obra de arte, de soberbia factura y admirablemente conservada, perteneció a un coleccionista fallecido hace bastantes años, habiendo debido su familia desprenderse de dicha joya artística. Parece que fue comprada a un negociante de antgüedades de esta ciudad por 5000 pesetas $»^{33}$.

La segunda, a los apuntes de Cayetano Barraquer Roviralta, empeñado tras la Desamortización y exclaustración posterior, en dejar testimonio de las vicisitudes por las que habían pasado los monasterios y conventos catalanes, tanto en lo patrimonial como en lo artístico. Aunque contiene errores, informa, sin embargo, sobre los actores de la venta: «Un amigo mío poseyó, sin duda heredada de su padre historiador y arqueólogo, una preciosa lápida de marmol procedente de un panteón de Santes Creus. Medía dos palmos en cuadro, y en bajo relieve representaba dos caballeros rindiendo sus lanzas. Su mérito artístico rayaba en grado superior. El indicado mi amigo quizá lo vendió al funestísimo para nuestras antigüedades Mr. Dupont, comerciante de objetos antiguos; y digo "quizá" porque me consta que mediaron fuertes controversias entre los dos. Al fin un Conde cuyo nombre me olvidé de apuntar, la regaló al Museo del Louvre de París (me lo dijo el mismo amigo a 6 de junio de 1907)» ${ }^{34}$.

Por último, el párrafo que sigue corresponde al redactado de un trabajo sobre escultura catalana de Félix Duran Cañameras. Aunque detectamos nuevamente errores de contenido, es indudable que se refiere a la misma obra que los anteriores: «En la col-lecció Dupont del Museu del Louvre hi ha un fragment en el que estan representats uns cavallers que porten escuts a la funerala, el més visible dels quals es el de Sicilia. Per aquesta raó s'ha dit que aquest fragment havia format part d'un sepulcre d'un infant de Sicilia. Nosaltres creiem que

ho és de la tomba reial de Doña Elionor de Sicilia, esposa de Pere III» ${ }^{35}$.

Estas tres fuentes, a pesar de entrar en contradicción entre sí en algunos puntos, coinciden en lo sustancial. En las proximidades de 1895 se había vendido en Barcelona un relieve de «mármol», de formato cuadrado (unos 45 centímetros de lado), que había formado parte de un sepulcro y que ostentaba figuras de caballeros armados «a la funerala», es decir, con las armas al revés, lo que señalaba su carácter funerario. Dos de las noticias hacen hincapié en las características heráldicas de los escudos que ostentaban estos caballeros: las armas de Aragón y Sicilia. Por otro lado, en dos casos se menciona también a quienes intervinieron en la transacción. Aunque en ningún momento se identifica al vendedor, se señala, no obstante, su parentesco con el fundador de la colección artística a la que pertenecía el relieve. Se trataba del hijo. Además, en dos ocasiones, se menciona el nombre de Dupont, en una de ellas erróneamente. El texto de Cayetano Barraquer Roviralta lo cataloga de «funestísimo para nuestras antigüedades» y en verdad debió serlo. Se trataba de Celestino Dupont, un importante anticuario radicado en Barcelona, que estando bien conectado con la Junta Municipal de Museos a la que vendió obras en distintas ocasiones ${ }^{36}$, tenía también buenos contactos con los anticuarios parisinos del momento, como lo prueba la reconstrucción del periplo de la pieza que estudiamos. La mención de este personaje en dos de las noticias que aportamos, hace plausible considerarlo el intermediario necesario en la salida del relieve desde Barcelona hacia París, donde pasó a formar parte de la colección del conde Isaac Camondo, constando como tal ya en $1897^{37}$. Desde allí, por donación, ingresó en el Museo del Louvre, donde permanece. Entre tanto, y como era

su interés como dato historiográfico en las peripecias del mismo.

34. C. Barraquer i Roviralta, Los religiosos en Cataluña durante la primera mitad del siglo XIX, vol. III, Barcelona, 1915, p. 382. Esta noticia fue aportada por mí en relación con este relieve en 1992: F. Español, Plorants del sepulcre de Ferran..., p. 241.

35. F. Duran i Cañameras, "L'escultura mitjeval a la ciutat de Tarragona", Butlletí Arqueològic de Tarragona (1923-1924), p. 173. Noticia relacionada por mi con el relieve que tratamos en F. EsPAÑOL BERTRAN, «Esteban de Burgos y el sepulcro de los Queralt en Santa Coloma (Tarragona)», D'Art, 10 (1984), p. 164, nota 92.

36. C. Barraquer i Roviralta, op. cit., vol. II-1, p. 333, vuelve a calificarlo de «funesto traficante», como lo hace en el párrafo citado en la nota 34. En 1897 vendió a la
Junta «un incensario románico, otro gótico, varios objetos de hueso y otros de cerámica española, por 600 pesetas» (J. GRAHIT I GRAU, op. cit., p. 90). En 1906 los comisionados de la Junta se acercaron a su establecimiento para ver una serie de obras. Una carta de Pijoan a Raimon Casellas del año 1906 habla de ello: «[... L'hi recordo que'l día 16 te d'anar a can Dupont per veure tota la retaulada que l'hi ha arrivat. Fermi els mellors, ab promesa de comprarlos. Axo no vol dir que ens haguem de carregar de matraca cuatrecentista. També procuri veure una creu de 1000 duros — segle xim esmalts- que en Dupont ens va ensenyar un dia. Si no l'ha venuda, fermila, que per 500 durots s'hauria de comprar. De coses com allo ya veura que no en corren. Es exemplar insignisim d'orfebre <re>ria. Item procuri que en Dupont no vengui per are el frontal de pedra d'Anglesola. of ereixin forses diners. Diguilhi que l'hi comprarem l'any vinent, que farem una suscripció $[\ldots]$ cualsevol cosa! pro que no fugi [...] aquella pessa. Encare que no agradi als nostres vocals ya'ls hó farem agradar. Fermila encare tres messos y yo l'hi aseguro que's comprara [...] Fem feyna, fem feyna! No's descuidi de anar a can Dupont [...]». (J. Castellanos, «Dotze cartes de Josep Pijoan a Raimon Casellas", Miscel-lània Aramón $i$ Serra (Estudis Universitaris Catalans, 3 a època), III (1983), p. 52-53).

37. E. Moulinier, «Un don du Musée du Louvre», Gazette des Beaux Arts, I (1897), p. 89-103, fig. p. 91. G. MigeON, «La collection de Isaac Camondo", Revue de l'art ancien et moderne, 39 (1914), p. 404. «La col-lecció Camondo al Louvre», Anuari de l'Institut d'Estudis Catalans, V (1913-1914), p. 928. 
común, en su camino hacia Francia el relieve perdió sus señas de identidad ${ }^{38}$, como lo revela una nota sobre la colección Camondo publicada en 1897, donde se presenta como procedente de Valencia. Evidentemente es el origen apócrifo que debió hacerse constar en la venta, lo cual indica una cierta prevención a declarar su origen exacto, perfectamente conocido por quienes intervinieron en la transacción. Quizá pesó en ello el antiguo compromiso de Joan Cortada de no deshacerse de esta obra, o puede que el celo puesto por entonces en la reconstrucción de Poblet. En uno u otro caso, haciéndolo, lo que se evitaban eran posibles reclamaciones incómodas. El precio, 5.000 pesetas, debió ser más que suficiente para convencer a quienes participaron en la venta de lo conveniente de la misma y un argumento a favor de evitar problemas innecesarios.

Los restantes elementos que en origen pudieron formar parte del sepulcro de Fernando de Antequera y que muestran afinidades estilísticas con el relieve estudiado hasta ahora, se hallan muy dispersos. Si en ciertos casos contamos con noticias puntuales relativas a sus ventas sucesivas, en otros no disponemos ni de eso. Existen, en primer lugar, las dos figuras conservadas en el museo del monasterio de Poblet (figura 4). Talladas conjuntamente e identificadas como procedentes del mencionado sepulcro, fueron atribuidas a Pere Oller por Agustí Duran i Sanpere en una publicación de $1934^{39}$. Se trata de sendas figuras de plorantes, en alto relieve, que, siendo contiguas la una de la otra, se conservaron durante un tiempo separadamente. Una de ellas formó parte de la colección Batlló ${ }^{40}$, para pasar luego a los fondos del Museo de Arte y Arqueología de Barcelona, donde permaneció hasta 1934 , en que se acordó reintegrarla al monasterio de Poblet, conjuntamente con otros elementos que le habían pertenecido ${ }^{41}$. Fue entonces cuando Duran Sanpere advirtió que la mano que sujetaba el brazo de una segunda figura conservada entera en Poblet, coincidía con el fragmento de este plorante de principios del siglo Xv. Mientras éste mostraba su cabeza encapuchada pero descubiertos tanto el rostro barbado como la mano izquierda que fue la que sirvió para devolver su disposición original a las figuras, en el caso del otro plorante el cuerpo quedaba camuflado totalmente por la indumentaria propia del duelo. Una gramalla cubría íntegramente el cuerpo y un velo tapaba el rostro, detalle éste último que apunta a su probable naturaleza femenina ${ }^{42}$.

El pintor y escenógrafo Oleguer Junyent (1876$1956)^{43}$, de quien son conocidas sus estancias en el monasterio ${ }^{44}$, poseyó al menos una pieza de estas mismas características ${ }^{45}$. Ignoramos como la adquirió, aunque es importante remarcar que la irrupción de este personaje en el mundo del coleccionismo parece coincidir con la desaparición de la colección Cortada. Por ahora, sin embargo, el posible paso de ciertas piezas pobletanas de una

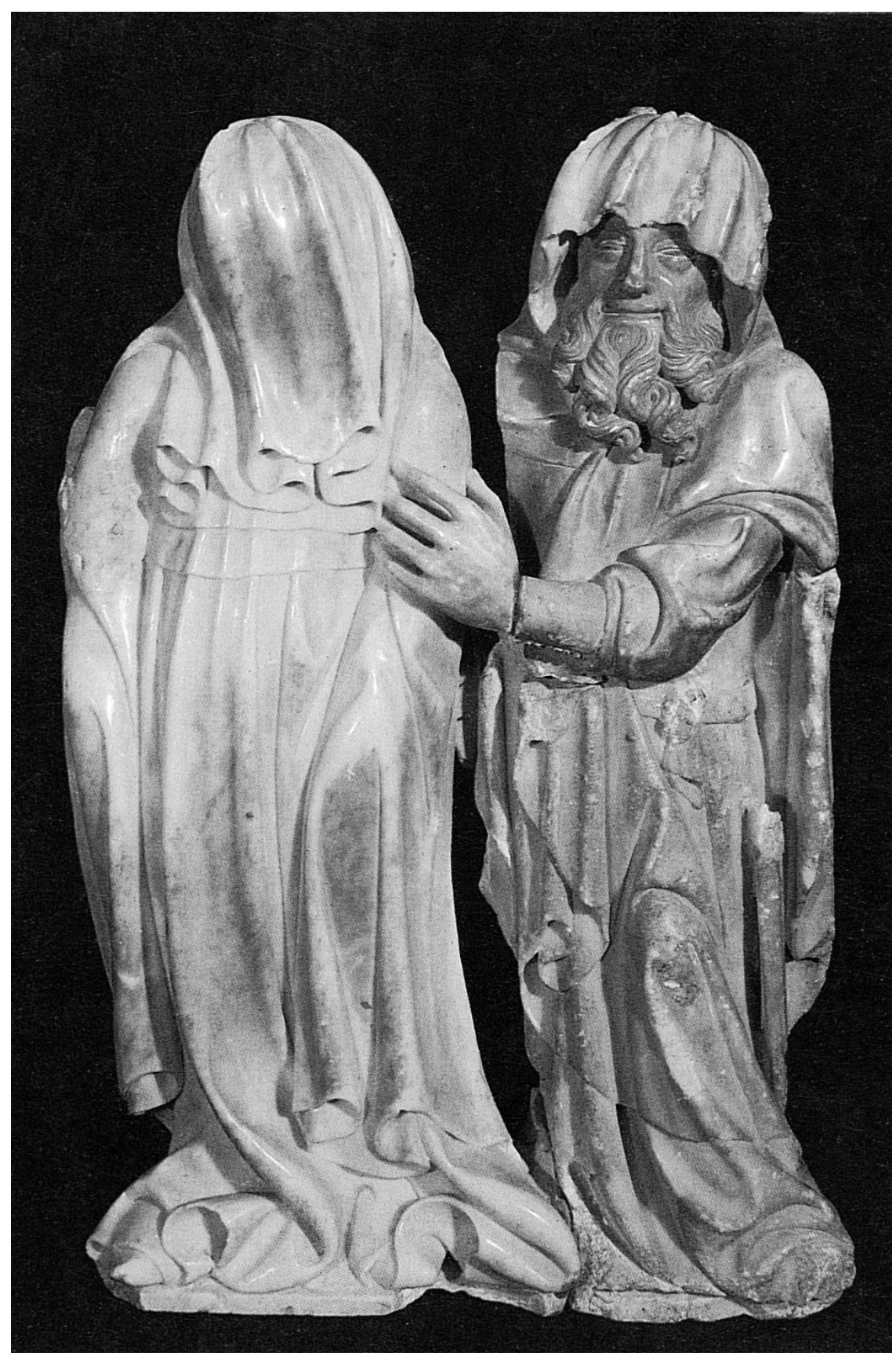

Figura 4

Pere Oller. Plorantes del Museo de Poblet.

38. Es un rasgo habitual en muchas obras hispanas que emigraron en los años finales del XIX, o a comienzos del xx, hacia el extranjero. Es un tema de trabajo que nos interesa particularmente $\mathrm{y}$ en el que hemos obtenido ciertos resultados. A título de ejemplo, recordemos el caso del frontal de sepulcro de mediados del siglo XIV, oficialmente «destruido» durante la guerra civil en Torà de Riubregós, en la Segarra, y reaparecido en el Museo de Bellas Artes de Boston, donde constaba con un origen apócrifo: una iglesia del sur de Francia (cf. F. EsPAÑOL, «El escultor trecentista Berenguer Ferrer: un eslabón más en la penetración del arte francés en Cataluña», Annario del Depar tamento de Historia y Teoría del Arte, II (1990), p. 89-91). Asimismo, los relieves funerarios en la actualidad propiedad del mismo museo americano, que habiendo salido a la venta en París como originarios de un convento de Barcelona, se vendieron y constan ahora en Estados Unidos como procedentes de Poblet (ídem, «Naixement. Bernat Roca", en Catalunya Medieval..., op. cit., p. 302-303). Por último, la imagen de un san Pedro trecentista custodiada en el Metropolitan Museum de Nueva York, que, siendo de la Seu d'Urgell, se catalogaba hasta ahora como oriunda del monasterio premostratense de les Avellanes (ídem, «El ressò de Rieux a les catedrals catalanes", Lambard, IX (1996) (1997), p. 259-267). Se trata de una práctica que estuvo bastante generalizada y de la que habla un testigo ocular del París de principios de siglo: F. MARÈs, El mundo fascinante del coleccionismo y las antigüedades. Memorias de la vida de un coleccionista, Barcelona, 1977, p. 79-80, 329.

39. Museo de Poblet, sin número de inventario. $37 \times 24,5 \times 6,5, \mathrm{~cm}$. Las dio a conocer Agustí Duran I SAnpere, Les escultures de Poblet a Poblet..., del mismo autor: Els Retaules..., vol. II, p. 29. 


\section{Figura 6.}

Pere Oller. Plorante de la antigua colección Homberg. Chicago, Museo de la Universidad de Loyola.

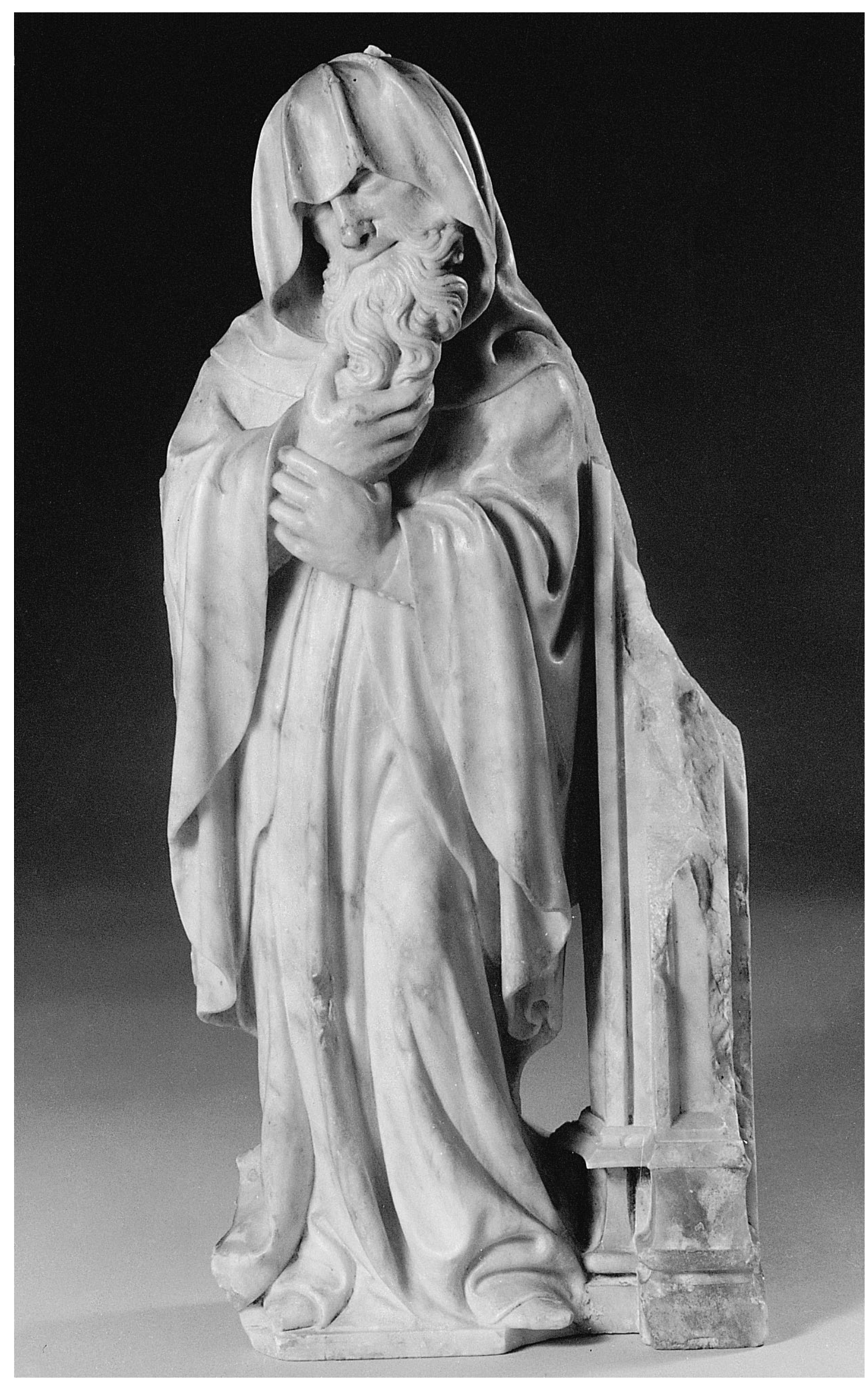




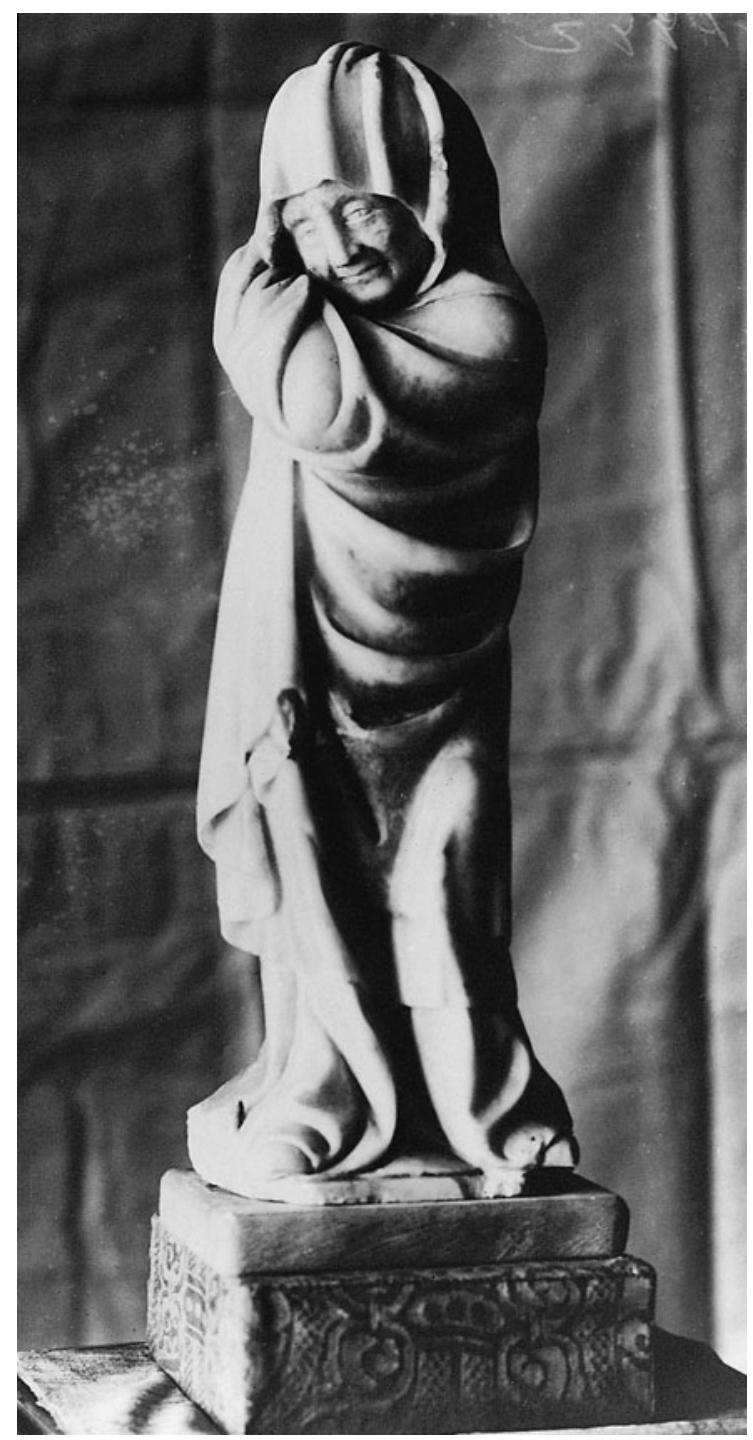

Figura 7

Pere Oller. Plorante de la antigua colección Terez. Más tarde perteneció a la colección Echaurren de Madrid. Paradero actual desconocido. (figura 6). En este caso, la peripecia de la pieza puede rastrearse con bastante detalle. Perteneció a la colección francesa de Octave Homberg que salió a la venta en París el año $1902^{51}$. Cambió de propietario en París nuevamente los años $1908^{52}$ y 1921. En esta última fecha pertenecía a Raoul Heilbronner ${ }^{53}$. Volvió a ser vendida en 1970 como parte de la «Collection de M.X...» ${ }^{54}$, y entonces, a través de la Galería Blumka de Nueva York, pasó al museo norteamericano. Se trata de un nuevo plorante masculino en un estado de conservación óptimo. Adosado por su izquierda a un elemento arquitectónico que le sirve de contrapunto, viste gramalla y cubre su cabeza con la capucha, aunque manos y rostro quedan a la vista. Destaca en su rostro una larga barba que sujeta con sus manos, lo que constituye un nuevo recurso al repertorio gestual propio del dolor. En un primer momento el plorante fue atribuido a Antoni Canet ${ }^{55}$. Las semejanzas de disposición, indumentaria y afinidades estilísticas que manifesta la figura con una de las que presiden el frontal del sepulcro del obispo Escales, en la catedral de Barcelona, son innegables. Sin embargo, dicha adscripción se corrigió muy pronto. A pesar de esos débitos, es indudable su menor calidad respecto a la que constituye su más directo punto de referencia. La pertenencia de la pieza al sepulcro pobletano que venimos analizando y su vinculación al arte de Pere Oller no parece plantear dudas, puesto que coincide con los restantes fragmentos, tanto en material y medidas como en estilo ${ }^{56}$.

Junto a estas piezas que, salvo el nuevo plorante dibujado por Milà i Fontanals, cuyo paradero ignoramos, y el perteneciente al Museo de la Universidad de Lawrence, eran ya conocidas por la historiografía, existen otras dos. Eran inéditas hasta que las presenté como parte de este sepulcro real en 1992, aunque sin acompañar mi texto de las correspondientes ilustraciones ${ }^{57}$. Se trata de una figura entera y del fragmento de una cabeza. Ignoro el paradero actual de la primera ${ }^{58} \mathrm{y}$, por tanto, se hace difícil establecer sus medidas, aunque el material y los detalles de la indumentaria del personaje, así como otra evidencia que presentaré en su momento, hacen inequívoca su pertenencia al frontal de un sepulcro, y su estilo a la producción de Pere Oller ${ }^{59}$. En 1877 pertenecía a José O. Terez y como tal fue expuesta en la exposición de artes suntuarias de Barcelona el año $1877^{60}$. Se trata de un nuevo plorante masculino, cuyo cuerpo aparece totalmente envuelto por el vuelo de su gramalla y cubierta su cabeza por la capucha, aunque sea visible el rostro (figura 7). La forma achatada de éste último, tanto como la resolución de sus rasgos, revela analogías muy elocuentes con el del plorante del Metropolitan Museum de Nueva York. Una de las particularidades más interesantes de la figura es su contrapposto. Ninguno de los otros
51. Catálogo de la subasta de la colección: O. Homberg, París, 1902, número de catálogo 704 con reproducción: «Statuetteapplique en marbre tendre blanc, représentant un pleureur debout, la tête inclinée, les mains croisées sur la poitrine. Auprès de lui, un fragment d'architecture. Fin du xve. siècle».

\section{Véase la nota 54}

53. «Fragment de Haut-Relief en marbre blanc sculpté représentant un saint moine, debout, vêtu d'une robe à capuchon. Il est adossé a un pilastre ornementé. Travail espagnol de Poblet, fin du XVe. siècle. haut $29 \mathrm{~cm}$.» (Collections Raoul Heilbronner, 20-21 de juny de 1921. Première Vente. Galerie Georges Petit, 8 rue de Sèze).

54. En esta venta, realizada en París en el Palais Galliera el viernes 9 de junio de 1970, se hace constar: Ancien. Collec. O. Homberg. Vente Galerie Georges Petit, 16 mai 1908.

55. F. Rowe, «The Martin d'Arcy Gallery of Art at Loyola University of Chicago", The Art Journal, XXXII (1973), p. 433438 , con reproducción del plorante en la portada.

56. Se manifestaron en estos tér minos: A. Altisent, Història.. p. 304-305 y M.R. MANOTE, $U n$ relleu català..., p. 28 , y yo misma: F. Español, Plorants del sepulcre de Ferran..., p. 241. En la actualidad las publicaciones del Museo norteamericano ya se hacen eco de esta nueva atribución.

57. Ibídem, p. 241.

58. Barcelona, Archivo Mas.

Cliché Gudiol 27442. La pieza se identifica como perteneciente a la colección Echaurreu de Madrid.

59. Aunque M.R. Manote (Correr les armes..., p. 100), al respecto de mi atribución, de esta pieza y de otro fragmento, al sepulcro real pobletano en 1992, escribe: «Español ens proposa també per aquesta tomba dues altres escultures de plorants - una, molt fragmentada, i l'altra, en parador desconegut - atribució a la qual és dificil adherirse», creo que la fotografía que ahora presento y los argumentos que esgrimiré más adelante, hacen evidente que las características formales y estilísticas de la misma, merecen cuanto menos un comentario algo más razonado para desestimarla como obra de Pere Oller y del sepulcro que tratamos.

60. En el catálogo consta como: «otra plañidera de un sarcófago, exhibida por Don José O. Terez». «Exposición de artes suntuarias (1878)». Álbum Heliográfico, Barcelona, 1878, p. 12, lámina 34. 
elementos conocidos del sepulcro real lo presenta. Por ello resulta tan significativo, según veremos, advertir la coincidencia que parece existir entre esta figura y uno de los plorantes del antiguo frontal sur del sepulcro situado en el extremo occidental del arco real emplazado en el lado sur, según se advierte en un dibujo de los panteones reales realizado con anterioridad a su destrucción. Junto a estos argumentos que apoyan la pertenencia de esta pieza al túmulo que estudiamos, es ocioso remarcar que el tratamiento de la zona baja de las telas, particularmente los pliegues que se generan sobre los pies de la figura, son idénticos a los que muestran los dos plorantes conservados en el monasterio, el de Nueva York y el de Chicago. Incluso la base sobre la que se asienta, muestra la misma proporción respecto a ella que se detecta en las restantes mencionadas.

En lo que atañe al pequeño fragmento custodiado desde antiguo en el monasterio de Poblet (figura 8 ), se trata de una cabeza masculina de alabastro, cuyas medidas son $7 \times 4 \mathrm{~cm}$. Se exhibe en la actualidad en una vitrina del Museo de la Restauración $^{61}$. La cara, a pesar de su deterioro, deja ver unos rasgos muy elocuentes, perfectamente parangonables con los que ostentan los jinetes del relieve del «correr les armes» y las dos figuras contiguas conservadas en el mismo monasterio. En consecuencia, su atribución al sepulcro de Ferran de Antequera es del todo coherente, constatación a la que se suma como argumento a favor, su pertenencia al fondo lapidario de Poblet, desde antiguo. Una vieja fotografía lo confirma ${ }^{62}$. Quizás estamos ante el testimonio aislado de una figura desaparecida, o bien de lo único que pervive de la cabeza del plorante custodiado en el Museo de la Universidad de Lawrence. En cualquier caso, el recuento de todos estos fragmentos nos sitúa ante un total de seis o siete figuras conservadas total o parcialmente, más un relieve de formato cuadrado que, no lo olvidemos, en una de las referencias que hemos aportado relativas a su venta, se identificaba como originario de un frontal de sepulcro pobletano: "procedente, al parecer, de la parte delantera de un sepulcro de Poblet» ${ }^{63}$, se nos dice respecto a él.

\section{Los arcos reales de Poblet durante el siglo xv}

Existen diversas fuentes que describen la disposición de los túmulos de los condes reyes y sus esposas, sobre los arcos emplazados en el lado de la Epístola (figura 10) y en el del Evangelio (figura 9), del transepto de la iglesia de Poblet. Fueron inhumados en ellos diversos miembros de la dinastía, desde Alfonso el Casto hasta Juan $\mathrm{II}^{64}$, pero, si durante el siglo XIV existe una relativa correspondencia entre la conclusión de las tumbas y el traslado a las mismas de los restos reales para los

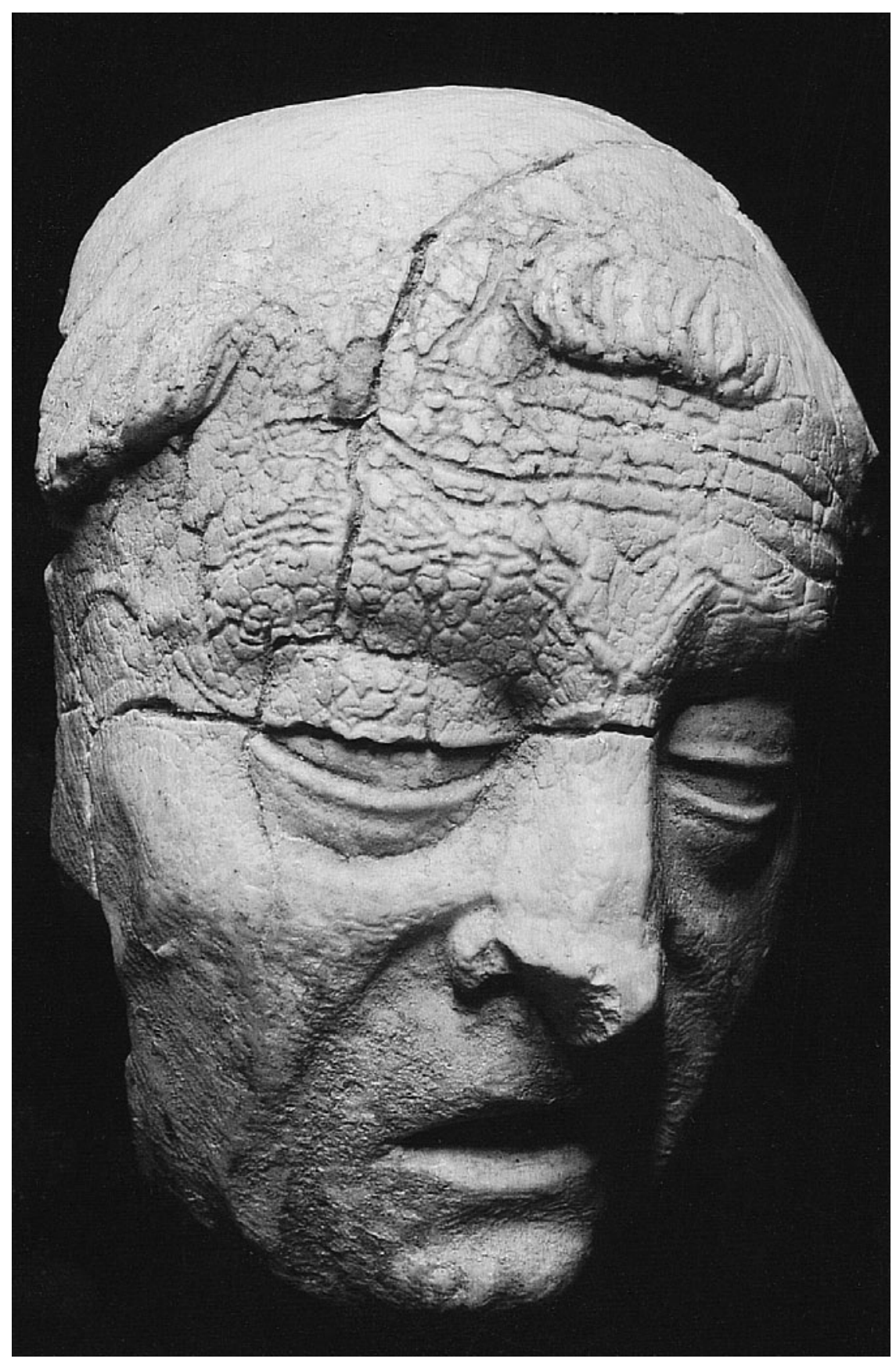

Figura 8.

Pere Oller. Fragmento de la cabeza de un intregante del cortejo funerario. Poblet, Museo de la Obra.

que éstas habían sido preparadas, no fue así durante el $\mathrm{XV}^{65}$. Hubo una gran desidia por parte de la monarquía a la hora de dar sepultura definitiva a Martín el Humano o a Alfonso el Magnánimo, actitud que corrigió Fernando el Católico actuando diligentemente con respecto a su padre Juan II.

Pedro el Ceremonioso, que fue el promotor de esta obra, pensó en incorporar unos baldaquinos de madera sobre los arcos, para protegerlos ${ }^{66}$. Su inclusión, a finales del siglo XIV, podría interpretarse como una forma de acabado final del proyecto, pero no era así. A la muerte del rey, estaban concluidos los sepulcros de Alfonso el Casto y Jaime el Conquistador ${ }^{67}$, el suyo ${ }^{68}$ y el de su primogéni- 


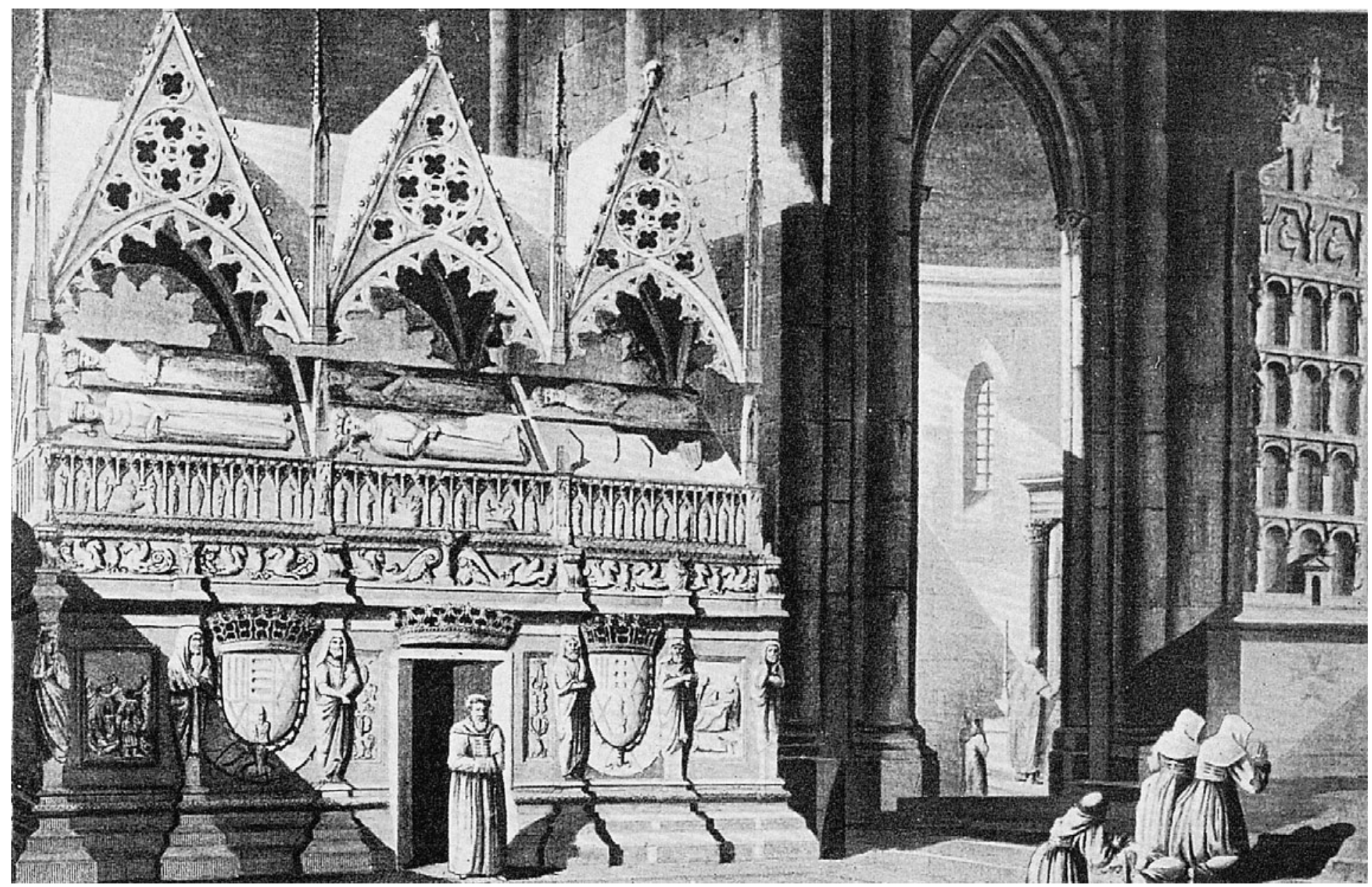

Figura 9.

Lámina LXXVI del Voyage Pittoresque, de Alexandre Laborde.

to $^{69}$. Mientras los dos primeros ocupaban el extremo oriental de ambos arcos, el suyo y el de Juan I, haciendopendant, se ubicaban en los espacios centrales respectivos. Quedaban, pues, por ocupar, sólo los otros dos del extremo occidental. A finales del siglo Xv, uno de esos huecos acogió el sepulcro del rey Juan II y de su esposa Juana Enríquez. Conocemos el nombre del artífice que lo ejecutó y el de su promotor. Fernando el Católico lo encargó a su escultor de cámara, el aragonés Gil Morlanes $^{70}$, para sus padres, siendo depositados sus restos en él, junto con los de una hija, la infanta Marina, en $1499^{71}$. Con esta empresa, conocida desde antiguo, se cierra la historia artística del panteón real de Poblet, que puede seguirse en sus más mínimos detalles a lo largo del siglo xiv, pero que está llena de interrogantes durante la práctica totalidad del xv. No sabemos qué sucedió exactamente con el sepulcro de Martín el Humano ${ }^{72}$, como no estamos seguros de saberlo en el caso de Fernando de Antequera ${ }^{73}$. Tampoco tenemos ninguna certeza en relación con el de Alfonso el Magnánimo ${ }^{74}$, puesto que el silencio de los historiadores domésticos respecto a él no descarta la posible existencia de un proyecto desconocido hasta ahora. Por este
61. Al dorso de la escultura figura el número 170 escrito en caracteres rojos. No consta número de inventario. Aunque no disponemos de las medidas, del fragmento conservado puede deduirse el equivalente de $35 \mathrm{~cm}$ de alto para la figura completa.

62. Barcelona, Archivo Mas.

63. Véase la nota 33.

64. Como excepciones recordemos los casos de Pedro el Católico, enterrado en Sigena; Pedro el Grande y Jaime el Justo que lo fueron en Santes Creus; Alfonso el Liberal y Alfonso el Benigno, inhumados, respectivamente, en la iglesia de los franciscanos de Barcelona y Lleida, y de Pedro, Condestable de Portugal, en Santa María del Mar, en Barcelona.

65. Para la historia del panteón real pobletano, véase: A. Altisent, Història ..., p. 261-296. También: J. BRACONS, "Operibus monumentorum que fieri facere ordinamus. L'escultura al servei de Pere el Cerimoniós», en: Pere el Cerimoniós i la seva època, Barcelona, 1989, p. 215-223.

66. Se confeccionaron a partir de 1381 (para el contrato: F. MARÈS,
La tumbas reales..., p. 202-204) Fue su artífice el carpinter Bernat Teixidor, radicado entonces en Vimbodí, aunque esta estancia puede ser temporal, pues Jordi de Deu, otro de los que in tervino en la obra del panteón, consta que fue obligado a trasladar su residencia a ese lugar cuando se incorporó en firme al proyecto en 1381. Para la obra de estos baldaquinos, véase: $\mathrm{A}$. Altisent, Història..., p. 287-288, y la noticia inédita que publicamos en el apartado 3 del presente estudio relativa a la policromía.

67. Ambos incluían en sus cubiertas una doble imagen yacente del difunto: su retrato como monje como rey, respectivamente. Proporciona esta descripción el texto de Vicente Prada publicado por R. DEL ARCO, op. cit., p. 567.

68. La cubierta estaba presidida por la imagen yacente del Ceremonioso en hábito diaconal, acompañada por otras tres femeninas que se han identificado como correspondientes a sus esposas, una de ellas con idéntica indumentaria, las dos restantes con vestido real. Deben identificarse como efigies de María de Navarra, Leonor de Portugal y Leonor de Sicilia, que son las que constan enterradas en el mismo sepulcro. Proporciona esta descripció Vicente Prada publicado por Del Arco (ibídem, p. 576).

69. La imagen yacente del rey y la de su segunda esposa Violante de Bar vestían hábito diaconal. Mata de Armanyac, guirnalda en la cabeza y corona real en las manos. Proporciona esta descripción el texto de Vicente Prada publicado por Del Arco (ibídem, p. 579).

70. Designado como tal en 1493 C. Morte García, «Miguel Ximénez y Gil Morlanes el Viejo, artistas de Fernando el Católico", en: Miscelánea de Estudios en Honor de D. Antonio Duran Gudiol, Sabiñánigo, 1981, p. 215-233.

71. Se hacen eco de ello diversos cronistas pobletanos desde el siglo xvi. Véase, al respecto: R. Del Arco, op. cit., p. 410 y

72. Para un estado de la cuestión: ibídem, p. 341 y s.

73. Para un estado de la cuestión: ibídem, p. 358 y s.

74. Para un estado de la cuestión: ibídem, p. 385 y 
75. Destaca entre las primeras el texto anónimo del siglo Xvi: Antigualles de Poblet, que fue publicado por R. DEL ARCO, Los sepulcros..., p. 449-555. En el siglo xvil redactó el suyo al abad Vicenç PRada, Sepulcros de la casa real de Aragón..., publicado de nuevo por R. DEL ARCO, Los sepulcros..., p. 556-695. En el XVIII lo hizo el padre Jaume Fortuny. Publica este último texto J GUITERT I FonTSERÈ, Colllecció de manuscrits inèdits de monjos del Reial Monestir de Santa Maria de Poblet, vol. 6, La Selva del Camp, 1949. Diversos testimonios confirman el eco que tuvieron esto memoriales entre los visitantes del monasterio desde el siglo XVI. M. MARCH, «Memoria sobre las tumbas reales de Poblet presentada a la reina Doña Germana de Foix», Boletín Arqueológico de Tarragona, XLV (1945), p. 63-66 H. Cооск, Relación del viaje hecho por Felipe II en 1585 á Zaragoza, Barcelona y Valencia, ed. A Morel Fatio, Madrid, 1876, p. 111-112. A. Ponz, Viage de España, vol. XIV, Madrid, 1788, $\mathrm{p}$ 220-225. A. LABORDE, Voyage pittoresque et historique de l'Espagne, París, 1806, comentario que acompaña la plancha LXXVI. Puede consultarse la edición seudofacsímil que se hizo de este volumen (con el texto traducido al catalán, acompañado de un prólogo y del correspondiente aparato crítico) de la que son autores O. VALLS y J. MASSOT (Abadía de Montserrat, 1974).

76. Véanse, al respecto, los comentarios de R. DEL ARCO, op cit., p. 350, 353, 361 y F. MARĖS, Las tumbas reales..., p. 134.

77. F. MARÈs, Las tumbas reales..., p. 235, apéndice 15.

78. A propósito de este documento, según se extracta en el manus crito de las Antiguallas de Poblet. véase R. DEL ARCO, op. cit., p. 533 «Elegim, diu, sepultura de nostr cos en la esglesia de Poblet, y volem que en aquella, prop lo sepulchre de nostres pare y mare sia feta en lo arch real una sepultura honrrosa peral nostre cos. Volem empero primer ser soterrat a la porta de la esglesia, en la claustra, ab sols una llosa damunt. pera quels que ixiran de la exglesia, o entraran, pasen per damunt nostra fosa».

79. J. E. Martínez Ferrando, «Exequias y enterramientos reales en la Corona de Aragón", Boletín Arqueológico de Tarragona, XLVII (1947), p. 57-84.

80. Para esta documentación: $\mathrm{F}$ MARĖs, Las tumbas reales..., p. $234-238$, doc. 15 a 17, y p. 242 243 , doc. 22. Otro instrumento real relacionado con la financiación del proyecto y fechado en $\mathrm{Za}$ ragoza a 25 de junio de 1399 , lo publica: M. D. Mateu Ibars, «E Mayoral de Quart, del priorato de San Vicente de Valencia, en el siglo XIV», VIII Congreso de Historia de la Corona de Aragón (Valencia, 1967), vol. II, Valencia, 1979, p. 268, doc. IV. motivo, abordar cuestiones artísticas relacionadas con el panteón a lo largo de este período encierra una gran complejidad. A ello se suma, naturalmente, la problemática derivada de la destrucción y dispersión posterior de sus elementos escultóricos.

A pesar de ello, como hemos visto, se han venido atribuyendo al sepulcro de Fernando de Antequera una serie de fragmentos, cuyo origen pobletano en la mayor parte de los casos está fuera de duda. De todos modos, ¿pertenecieron realmente a este túmulo? Hay que reconocer que la respuesta no es fácil. En el monasterio, de acuerdo con los documentos que obraban en su archivo, se redactaron diversos memoriales sobre los enterramientos reales que custodiaba, lo que a lo largo de los siglos XVI, XVII y XVIII facilitó la identificación de los sepulcros a los visitantes notables, y constituyó un género de memoria histórica en la que sustentar el prestigio de la casa ${ }^{75}$. No obstante, el redactado se hizo pensando en aquellos cuerpos que estaban depositados en el interior de los sarcófagos, y no en quienes o para quienes se habían confeccionado los mausoleos, en origen. Es una cuestión de matiz importante que no perderemos de vista en las reflexiones que dedicaremos seguidamente a toda esta problemática.

De acuerdo con estas descripciones, el cadáver de Fernando de Antequera se hallaba en el sarcófago dispuesto en el extremo occidental del arco del lado del evangelio, que era contiguo al destinado a Pedro el Ceremonioso y tres de sus esposas, situado en el centro, mientras que el del extremo oriental lo ocupaba el cadáver de Jaime el Conquistador. Naturalmente, de esta constatación se desprende un lógico interrogante: ¿Fernando I fue inhumado en un sepulcro labrado ex professo o se aprovechó el que había preparado para sí Martín el Humano? ¿Éste último llegó a existir realmente? Indudablemente, dar respuesta a estas preguntas es difícil. Fueron precisamente las reservas que manifestamos nosotros ahora, las que han llevado a algunos historiadores a considerar en algún momento que Fernando I debió de ser enterrado en el mausoleo reservado para Martín el Humano. Incluso, para conciliar determinados datos históricos que parecían ser contradictorios entre sí, se aventuró la posibilidad que Fernando I hubiera sido depositado en un sepulcro en el que se aprovecharon los elementos labrados previamente para el de su antecesor ${ }^{76}$.

Los documentos conocidos sobre el panteón pobletano hasta hoy, informan de la existencia de algún género de actividad en el sepulcro del rey Martín. En circunstancias menos complejas que la pobletana, estos instrumentos hubieran ahuyentado cualquier género de duda sobre la «realidad» de dicho mausoleo, pero en este caso las reservas se han mantenido más allá de lo común. Sólo puede haber un motivo que lo justifique: aceptar ese hecho suponía cuestionar la exactitud de los numerosos registros de enterramientos reales de Poblet que pasan por alto la realidad de un monumento propio del rey Martín, simplemente porque hablan de una cosa distinta al proyecto artístico, dado que contabilizan cadáveres, y el de ese monarca estaba depositado entonces en la zona baja de los arcos, dentro de un ataúd de madera.

Que Martín el Humano dispuso enterrarse en Poblet como lo habían hecho sus antepasados más inmediatos, es decir, en un sepulcro monumental que debía emplazarse en uno de los dos espacios libres existentes sobre los arcos, lo prueban distintos documentos, el más explícito de los cuales en un fechado en 1397, donde se lee: «in ecclesiam Monasterii Populeti in capite videlicet cori prioris inmediati post sepulturam dicti domini genitoris nostri eligimus sepulturam» ${ }^{77}$. Esta disposición se repite en su testamento de $1407^{78}$, a pesar de que en él también manifiesta su propósito de disponer de un enterramiento humilde, hecho que ha llamado la atención a los historiadores ${ }^{79}$. Se trataba, no obstante, de la sepultura provisional hasta culminar la corrupción del cadáver. Por este motivo, desde 1399 un escultor desconocido parece haber estado implicado en el mausoleo definitivo del monarca, bien en su diseño previo, bien en los trabajos iniciales del mismo. Varios documentos repartidos entre 1398 y 1402 lo confirman ${ }^{80}$. Se trata de disposiciones relativas a la financiación del proyecto, e indicaciones, correspondientes al año 1402, sobre el material a emplear, que no era otro que el alabastro aragonés de las canteras de Gelsa, en los Monegros $^{81}$, con el que había sido confeccionado el mausoleo del noble Pedro Fernández de Híjar, en el contiguo monasterio de Rueda de Ebro ${ }^{82}$. El rey, a su paso por el lugar, había quedado impresionado por la blancura del material — lo cataloga de «pedra blanca molt bella»- y escribió al abad de Poblet dándole instrucciones al respecto ${ }^{83}$.

Nada sabemos sobre este escultor. El período que media entre 1398 y 1402 coincide con un período de gran actividad edilicia en Poblet. En el sector occidental del claustro se construían entonces las cámaras reales bajo los auspicios del monarca. Por este motivo, un equipo de lapicidas se había instalado en el cenobio trabajando a las órdenes de Arnau Bargués ${ }^{84}$. Por las fechas en las que nos movemos, es dudoso que entre los responsables de estos trabajos se hallara Pere Oller, pues faltaba un tiempo para su plena irrupción en el panorama artístico catalán. Por tanto, si hay que considerar en firme la existencia de cierta actividad en el sepulcro de Martín el Humano, hay que pensar necesariamente en otro artífice.

De lo que no hay duda, es del posible destino que se habría dado al túmulo caso de haber existido: el extremo occidental del arco norte, donde lo había dispuesto por testamento el mismo rey. Si el 
sepulcro se confeccionó, dejando al margen que el cadáver de Martín el Humano no fuera trasladado a Poblet hasta muchos años después, al fallecimiento de Fernando de Antequera, quedaba disponible únicamente un sitio sobre los arcos reales donde colocar el nuevo sepulcro. Este aspecto, aparentemente sencillo, es el que en nuestra opinión se ha dejado de lado al evaluar la cuestión del panteón real a lo largo del xv. Aunque los memoriales sitúen el enterramiento de Fernando de Antequera, precisamente en el lugar elegido por Martín el Humano, se trata en todos los casos de fuentes que no son anteriores al siglo Xvi y que, en consecuencia, tienen en cuenta el estado de cosas en el momento en el que escriben, no la progresión de los hechos conforme se dieron en el tiempo. Cabe pues plantear una pregunta: ¿el sepulcro de Fernando de Antequera ocupó siempre el mismo lugar?

De todas estas fuentes domésticas, la más antigua y la que sienta las bases, porque no hay duda que inspiró a las que se redactaron posteriormente, es la que lleva por título Antigualles de Poblet. Según este manuscrito, el cadáver y el sepulcro de Fernando I - porque naturalmente no distingue uno de otro- ocupan el extremo occidental del arco norte o del Evangelio, mientras que el cadáver y el sepulcro de Juan II se sitúan en ese mismo lugar, pero en el arco del lado opuesto. Obviamente, no hay sitio para Martín el Humano. De él se nos dice que sus restos llegaron a Poblet en 1460, tras estar cincuenta años depositados en la catedral de Barcelona, y que su ataúd de madera se dispuso en el lado norte del presbiterio de Poblet $^{85}$. La peripecia del cadáver del rey Martín contenida en las Antigualles es cierta, puesto que puede contrastarse con fuentes contemporáneas. Una de ellas, el Dietari o Llibre de Jornades de Jaume Safont, que confirma que el viernes 25 de enero de 1460, un grupo de monjes de Poblet se hizo cargo de los despojos del rey Martín y de la reina Violante de Bar que hasta entonces habían permanecido en la catedral de Barcelona, y los trasladaron a Poblet ${ }^{86}$. Remarcamos este dato, por cuanto en una carta posterior de Fernando el Católico, hallamos una información que podría dar pie a interpretaciones contradictorias, cuando a todas luces se trata de un error.

Lo lógico, en vista de los hechos presentados hasta ahora, sería deducir que en Poblet no existía un sepulcro monumental en el que inhumar a Martín el Humano. Y ésta es la interpretación que ha aceptado mayoritariamente la historiografía, ignorando que, de haber sido así, buena parte de la inquietud que deja entrever la carta enviada por Fernando el Católico a su lugarteniente general, en lo concerniente a la ubicación del sepulcro de sus padres, no hubiera tenido sentido. Después detallaremos cual es esta misiva y en que términos se expresa el rey a este propósito. Con- cierne ahora resituar el problema de los espacios disponibles sobre los arcos, para entender su verdadero alcance.

Si nos planteamos a modo de hipótesis que el sepulcro de Martín el Humano se llevó a término y se ubicó donde estaba previsto, al fallecer Fernando de Antequera sólo quedaba ya un espacio libre sobre los arcos: el extremo occidental del situado en el lado sur, o de la Epístola. Por tanto, sería ahí donde se habría emplazado el nuevo mausoleo ejecutado por Pere Oller, de cuya existencia, a pesar de lo avaro de la referencia documental, no dudamos, puesto que los restos escultóricos conservados que hemos presentado en el apartado precedente, constituyen una prueba irrefutable. Si en el desarrollo de los hechos que tienen que ver con el panteón pobletano, hubieran sido coetáneos los proyectos artísticos y las inhumaciones, probablemente las descripciones que tendríamos del panteón a partir del siglo xvi reflejarían el estado de cosas que acabamos de adelantar como hipótesis. Pero como no hubo tal correlación de los hechos y, entre tanto, además, se produjo un cambio dinástico, hay que pensar que los vivos modificaron la voluntad de los muertos.

Recordemos que, según refieren todos los cronistas pobletanos desde el siglo XVI, el cadáver de Fernando I se hallaba en un sitio distinto al que acabamos de proponer como probable. Insisten, al respecto, en que tras su muerte permaneció depositado en un ataúd de madera en la zona baja hasta su traslado definitivo en 1499 al sepulcro emplazado en el extremo occidental del arco norte, es decir, justo en el lado opuesto. Sin embargo, el hecho de recurrir a esta fecha que tiene una innegable base histórica, no descarta la existencia de unos hechos previstos que se desprenden de la misma documentación.

Importa señalar, previamente, que para desentrañar esta problemática debemos abordar una cuestión cargada de ambigüedad, de la que ya hemos puesto sobre aviso: no es lo mismo hablar de sepulcro que de cadáver, y los cronistas domésticos siempre están más interesados en lo segundo que en lo primero. Es así en todos los casos salvo en uno. El abad Vicente Prada, a propósito del enterramiento de Fernando I, escribe:

En 15 de Abril del sobredicho año 1416 fue sepultado en Poblet en tumba de madera baxa, en el Presbiterio, en la cual estuvo hasta el año 1499, quando fue colocado en el primer sepulcro del arco Real, que está à mano izquierda entrando del Coro al Presbiterio; aunque al obrarse el Coro, año 1433, estaba ya hecha la sepultura ${ }^{87}$.

El mismo cronista, algo más adelante, al hablar de Juan II, vuelve a proporcionarnos nuevos datos de gran interés. Escribe al respecto:
81. Este alabastro, muy reputado en los siglos medievales, se utilizará en otros proyectos artísticos catalanes (p. e. el bancal añadido al retablo mayor de Lleida, a comienzos del siglo xv), pero la referencia sobre su empleo en el sepulcro real pobletano es la más antigua que conocemos.

82. El sepulcro, tras años de abandono en el monasterio de Rueda, se conserva desde 1915 en el Museo de Bellas Artes de Zaragoza.

83. Publican el documento: D. GiRona Llagostera, «Epistolari del Rei En Martí d'Aragó (13961410)», Revista de la Asociación Artístico Arqueológica Barcelonesa, VII (1909), p. 188-189. A. RuBió I Lluch, Documentsper l'historia de la cultura catalana mig-eval, vol. II, Barcelona, p. 364-365, doc. 378.

84. Se conoce la progresión de este proyecto por un registro de Cancillería que dio a conocer parcialmente hace unos años: J. GUITERT I FONSERÈ, Real Monasterio de Poblet, Barcelona, 1929, p. 172178. Lo ha publicado íntegramente ahora: M. R. TERES I TOMÀs, «El Palau del Rei Martí a Poblet: una obra inacabada d'Arnau Bargués i François Salou», D'Art, 16 (1990), p. 36-39.

85. Véase la edición de este texto en: R. DEL ARCo, op. cit., p. 476. Las Antigualles de Poblet se redactaron en 1587, mucho antes de construirse las cámaras sepulcrales de los Cardona bajo los arcos reales, momento en el que el ataúd de Martín el Humano pasó a su interior.

86. Edición a cargo de J. M. Sans i Travé, Barcelona, 1992, p. 118-119.

87. R. DEL ARCO, op. cit., p. 583. 
88. R. DEL ARCO, op. cit., p. 603.

89. J. Ametllen, Alfonso $V$ de Aragón en Italia y la crisis religiosa del siglo XV, vol. I, Gerona 1903, p. 327. A. RYDER, Alfonso the Magnanimous. King of Aragon, Naples and Sicily 13961458, Oxford, 1990. Nosotros citamos a partir de la traducción castellana: Alfonso el Magnánimo rey de Aragón, Nápoles Sicilia (1396-1458), Valencia, 1992, p. 231-232.

90. J. SAFOnT, Dietari o llibre de jornades..., p. 118-119.

91. Ibídem..., p. 277.

92. La publica F. MARÈs, Las tumbas reales..., p. 244-246, doc. 24.

93. Sobre este artífice: M. SERRANO SANZ, «Gil Morlanes, escultor del siglo Xv y principios del XVI», Revista de Archivos, Bibliotecas y Museos, 35 (1916), p. 351-380 36 (1917), p. 92-102; 37 (1917) p. 357-359, y los trabajos que se ci$\tan$ en las notas que siguen. L bibliografía sobre el escultor deja de recoger un dato aportado por varios historiadores del monasterio, según el cual desde 1501 dirigió las obras del claustro alto de Poblet, impulsadas por el abad Antoni Buhada. Lo recogen, entre otros: J. GUITERT I FONTSERÈ, Realmonasterio..., p. 216. R. DEL Arco, op. cit., p. 361.

94. Véase la nota 70.

95. F. Marìs, Las tumbas reales..., p. 245, doc. 24.

96. Fernando II estuvo en Poblet en tres ocasiones: el 1 y el 2 de noviembre de 1480, del 9 al 11 de octubre de 1493 y a mediados del mes de abril de 1503 (Cf. A Romeu de Armas, Itinerario de los Reyes Católicos, Madrid, 1974, p. 76 y s. Sobre esta visita, también: J. Finestres Y DE Monsalvo, Historia de el Real Monasterio de Poblet, vol. IV, Cervera, 1756, p. 65-72. A. Altisent, Història..., p. 448 y s.

97. M. C. MorTe Garcia, Miguel Ximénez y Gil Morlanes..., p. 221.

98. Finestres fue el primero en publicar el dato, pero antes que él lo habían recogido una serie de cronistas pobletanos. Es el caso de Vicenç Prada (1678), que es cribe: «el rey Catholico, a sus expensas, hizo fabricar los dos sepulcros del Rey Don Fernando el $1^{\circ}$ y del Rey Don Juan el $2^{\circ}$, como hoy se ven. Llamabase Gi Morlan el artífice que los labró, y concluidos fue colocado este Rey en 4 de mayo, año 1499 , con su muger la Reina $\mathrm{D}^{\mathrm{a}}$ Juana, y una hija de ambos, dicha $\mathrm{D}^{\mathrm{a}}$ Marina difunta en su primera edad, en el sepulcro más cercano al organo, muy diferente en imagineria à los otros» (cf. Del Arco, op. cit., p. 605). También se hace eco de esta noticia el padre Fortuny, que si gue fielmente al anterior (cf. J. GUITERT I FONTSERĖ, Col-lecció de manuscrits inèdits..., vol. 6, p. 95
Juan II murió el Rey en Barcelona, à 17, otros que à 19, de Henero, año 1479, en los 84 de edad. Tuvo sepultura baxa en el Presbiterio, hasta que el Rey Catholico, a sus expensas, hizo fabricar los dos sepulcros del Rey Don Fernando el $1^{\circ}$ y del Rey Don Juan el $2^{\circ}$, como hoy se ven. Llamabase Gil Morlan el artifice que los labró, y concluidos, fue colocado este Rey en 4 de mayo, año 1499, con su muger la Reyna Doña Juana, y una hija de ambos, dicha Doña Marina, difunta en su primera edad, en el sepulcro más cercano al organo, muy diferente en la imagineria à los otros [...] Los monges por sus mismas manos pusieron en las urnas esse dia los cuerpos de estos Reyes, y el del Rey Don Fernando el $1^{\circ}$ en la frontera, à la parte del Evangelio ${ }^{88}$.

Puede advertirse que entre ambos párrafos existe una contradicción. Mientras en el primero se alude a la existencia previa del sepulcro de Fernando de Antequera (que se da como hecho ya en 1433), en el segundo la obra se atribuye a Gil Morlanes, que lo habría ejecutado conjuntamente con el de Juan II y Juana Enríquez, en los años finales del siglo xv. Como podemos colegir, esto que se afirma en segundo lugar no es posible por varias razones. No sólo por la existencia de los fragmentos escultóricos que hemos presentado como obra de Pere Oller, o en todo caso del período artístico en el que el escultor trabaja, sino por los propios términos que usa Fernando el Católico al hablar del panteón real en la carta a su lugarteniente, de la que trataremos inmediatamente. No es posible imaginar el sepulcro de Fernando de Antequera como obra de Morlanes, pero, con matizaciones, la afirmación puede encerrar una parte de verdad.

Junto a ésta, hay otra cuestión a subrayar. El historiador, como lo harán los restantes cronistas de Poblet, insiste en la contemporaneidad de las inhumaciones de Fernando I y de Juan II y su esposa e hija. Las sitúa en 1499 , pese a que nos advierte que el sepulcro de Fernando de Antequera ya existía en 1433, cuando se construyó el coro. Para no entrar en contradicciones excesivas, salva la cuestión señalando que los restos de Fernando de Antequera habían permanecido en un lugar provisional hasta entonces: dentro de un ataúd y en bajo, el mismo sistema que sabemos fue el utilizado en el caso de Martín el Humano. Llegados a este punto, se hace obligado preguntarnos hasta donde el cronista hace aquí una interpretación personal, o se basa en documentos históricos para afirmar tal cosa. Por desgracia, no disponemos de datos fidedignos para cerrar esta cuestión, que entendemos clave en nuestra argumentación. Lo que sí podemos, en cambio, es manifestar nuestras sospechas: creemos que se trata de una interpreta- ción para poder encajar todas las piezas del rompecabezas. Probablemente, al considerar los datos históricos conocidos, percibió las mismas contradicciones que se nos han planteado a nosotros, y no vio otro modo de explicar los hechos que el que comentamos. Dado que el cadáver de Martín el Humano había permanecido en un ataúd de madera tanto tiempo, «dedujo» que el de Fernando de Antequera habría seguido la misma suerte, puesto que no se le había enterrado hasta 1499. Sin embargo, al hacerlo, pasaba por alto un detalle: a diferencia de Martín, los restos del rey Fernando I estaban en Poblet desde el mismo momento de su muerte y, por tanto, existía coincidencia temporal entre el óbito y la obra del mausoleo, si éste se ejecutó cómo y cuando creemos. No había, pues, razón alguna para no inhumarlo en ese sepulcro monumental una vez concluido - a buen seguro, el que el propio cronista da por terminado en 1433, al construirse el coro-. Esta nueva presentación de los hechos que proponemos, exige explicar por qué hubo que enterrar de nuevo a Fernando I en 1499 y por qué trabajó en su sepulcro Gil Morlanes, y lo haremos de inmediato. Pero previamente, y a favor de esta correlación de los hechos que estamos intentando plantear, queremos invocar una noticia que proporcionan José Ametller y Alan Ryder al tratar sobre el Magnánimo, por desgracia sin citar la fuente de que se sirven. Informan ambos de la estancia de Alfonso en Poblet en febrero de 1432, para asistir a la inhumación de su padre en el sepulcro monumental recién terminado ${ }^{89}$.

Aceptada esta noticia que acabamos de aportar, al depositar el cadáver de Fernando de Antequera en el lugar que en 1432 quedaba libre (el extremo occidental del arco sur), el panteón real estaba completo. No había sitio para nuevos sepulcros, aunque uno de ellos, el de Martín el Humano - insistimos en que debe presumirse su existencia, para entender el desarrollo posterior de los hechos-, no contenía el cadáver del rey al que estaba destinado, puesto que éste no llegó a Poblet hasta 1460. Además, si el traslado definitivo se realizó entonces, fue por el interés de los monjes y ante la absoluta indiferencia de Juan II, que se negó a financiar incluso un traslado solemne de los restos, según lo solicitaban los consejeros barceloneses, y como correspondía a la dignidad de su predecesor $^{90}$. Es importante advertir la actitud poco respetuosa del rey, porque probablemente en ella está la clave de lo que sucedió luego con el cadáver. Martín el Humano formaba parte de una línea dinástica extinta, mientras que Juan II encarnaba a los Trastámara, vinculados a la Corona de Aragón desde el reinado de Fernando de Antequera. De acuerdo con esa realidad, resultaba más imperioso hallar un lugar en los arcos reales para los miembros de la nueva dinastía que para los de la precedente. 


\section{El sepulcro de Juan II}

Juan II falleció en Barcelona en 1479 y su cuerpo fue trasladado a Poblet, al concluir las exequias ${ }^{11}$. La carta enviada en 1490 por Fernando el Católico a su lugarteniente ${ }^{92}$, nos informa que estaba por empezar la obra del sepulcro que consta concluido, sin embargo, en 1499, cuando fueron trasladados a él los cuerpos de Juan II y Juana Enríquez y de la hija de ambos, la infanta Marina. Lo realizó el escultor aragonés Gil Morlanes ${ }^{93}$ y se ubicó en el extremo occidental del arco sur. Los detalles de la marcha del proyecto, cuyo desarrollo hay que situar entre 1493-1499, es decir, a partir del nombramiento de Morlanes como escultor real ${ }^{94}$, nos son desconocidos. Sin embargo, como hemos ido advirtiendo, existe una cuestión que para nosotros está fuera de duda respecto a él. Cuando Fernando el Católico planeó la obra del sepulcro monumental para sus padres, se encontró con un problema: en la zona superior de los arcos reales, el lugar que por dignidad les correspondía ocupar, ya no había sitio. No veo que se puedan interpretar en otro sentido los comentarios vertidos en la carta a su lugarteniente:

Ya sabeys como sta alli el cuerpo del serenisimo rey don Johan, nuestro padre y senyor de inmortal memoria, el qual fasta qui ni tiene fecha tumba ni ordenado el lugar donde ha d estar. $\mathrm{Y}$ mas stan por traher alli los cuerpos de los serenissimos reyes don Martin y don Ferrando, nuestro agüelo de indeleble memoria, los quales han de ser collocados. E porque nos tenemos voluntat, en todo caso, con la presencia nuestra ordenar las suas sepulturas e collocarles cada huna en su lugar, como quien son y es de razon ${ }^{95}$.

A pesar del error que se desliza (el monarca cree que el cadáver de Fernando de Antequera, como el de Martín el Humano, aún no está en Poblet) descubre su preocupación por el espacio disponible. No sabemos si esa voluntad de «ordenar las suas sepulturas e collocarles cada huna en su lugar, como quien son y es de razon», motivó su visita al monasterio en octubre del $1493^{96}$, pero lo cierto es que esta estancia encaja muy bien con la marcha posterior del proyecto: algo más de dos meses después, el 23 de diciembre, Gil Morlanes era nombrado su «pedrero e esculpidor de ymagineria de pedra e de madera ${ }^{97} \mathrm{y}$ debía empezar la obra del nuevo sepulcro real.

Hasta hace poco, el único documento conocido sobre esta empresa era el publicado en el siglo XVIII por Jaume Finestres. Se trata de una noticia indirecta donde, al detallar el abad en carta al rey los pormenores de la inhumación definitiva, entre otros, del cuerpo de Juan II en su sarcófago monumental el 4 de mayo de 1499, menciona entre los asistentes al acto a «Egidio Morlan, obrero de los sepulcros» ${ }^{98}$. A esta noticia, que ha tenido hasta hoy una gran fortuna historiográfica y de la que hemos hallado una nueva versión ${ }^{99}$, se han sumado otras dos más estos últimos años. La primera la publicó Steven Janke ${ }^{100}$; la segunda, Carmen Morte ${ }^{101}$. Se trata de sendos pagos al escultor por su intervención en la obra. El primero está fechado a 29 de marzo de 1496; el segundo, en marzo de 1503. De los dos, el de 1496 informa sobre su costo total: 300 ducados de oro.

A estos datos conocidos puedo añadir uno nuevo de 1496. Lo hemos extraído del mismo manuscrito pobletano inédito que nos proporciona otros datos sobre el panteón real, que iremos presentando oportunamente. Dice así:

1496 fonch feta avinença entre mestre Gil Morlan de Çaragosa imaginayre del Sr. rey e mestre Juan de Rua pintor de Muntblanch, ço es que mestre Joan aja de pintar los tres tabernacles de les tombes reals de la banda del cor de (l')abat y que ell mateix se faxa la despesa y se cerque or, colors e obre, y lo dit mestre Gil li done norante lliuras. Consta en lo manual de fra Pere Davins monje y notari de Poblet. Llavors se feya la tomba del rey en Joan II segons consta apocha de dit preu ${ }^{102}$.

Morlanes en 1496 ya trabajaba en Poblet, y en calidad de escultor de cámara coordinaba otras intervenciones contemporáneas en el panteón real, concretamente, la pintura del baldaquino que cobijaba el arco sur, labrado a finales del siglo XIV por el carpintero afincado en Vimbodí, Bernat Teixidor ${ }^{103}$. El pintor que se cita como responsable de los trabajos es Juan de Rua de Montblanc. Se trata de un artífice desconocido hasta ahora, pero que debe tener algún parentesco con el Jeroni de Rua, que consta como vecino de Montblanc en el siglo XVI ${ }^{104}$.

Hemos ido advirtiendo que la atribución del sepulcro de Fernando de Antequera a Gil Morlanes, de la que se hacen eco distintos cronistas pobletanos, podía encerrar una parte de verdad. Creemos que la nueva presentación de los hechos que proponemos lo hace verosimil, pero para ello no puede perderse de vista lo que venimos sosteniendo hasta ahora: a nuestro juicio, en Poblet, cuando se aborda la obra del sepulcro de Juan II existían los sepulcros de Martín el Humano y Fernando I, el primero sin el cadáver del rey. Evidentemente, si para acomodar el sarcófago destinado a Juan II había que sacrificar uno, el más factible de los dos era el de Martín por ese mismo motivo. Imaginemos qué es lo que pudo ocurrir en este caso: Gil Morlanes desembaraza el lugar ocupado por el mausoleo de Fernando de Antequera para ubicar el de Juan II, y traslada el primero al lado contrario, eliminando total o parcialmente el túmulo destinado a Martín el Hu-
Traduce el documento y lo publica entero: J. Finestres y DE Monsalvo, op. cit., vol. IV, p. 80. P. Piferrer, F. PARcerisa, Recuerdos y Bellezas de España. Cataluña I, Barcelona, 1839, p. 306. M. SERrano SANZ, Gil Morlanes, escultor..., p. 367, nota 1. J. GUITERT I FONTSERÈ, Real monasterio..., p. 215-216. R. DEL ARCO, op. cit., p. 413-414.

99. «L'any 1499, dissapte, a les deu hores de la matinada a 4 dies de maig, foren sepultats lo rey en ferrando primer sobre larch real de la tomba mes prop a la cadira del prior y diu la carta que aquesta tomba ya avia temps que era feta. E lo rey en Joan segon ab la reyna dona Juana, sa muller segona y la Infanta dona Maria, sa filla, en lo altre arch en la tomba mes prop la cadira del abat, la qual tomba avia feta novament un maestre Morlan per manament del rey Catholic lo qual apres scriu al abat y convent fahent los gracies de la solemnitat ab que havia feta la dita tumulació. Digueren primer offici de defunts solemne y lo abat de Benifaça qui havia precedit en la nova electio del abat Buada digue la missa de pontifical $\mathrm{y}$ apres se foren ensoltes y solemnes exequies y lo prior y altras monjos ab lo dit Morlan Posaren de ses mans los dits cossos en les tombes» (Girona, Archivo Diocesano, ms. 14., fol. 84). Para este manuscrito, inédito hasta hoy, véase la nota 113 .

100. R. S. Janke, "Gil Morlanes the Elder: Gothic Works Restudied", The Fifteenth Century, Acta, XII (1985), p. 6180. Para la traducción castellana: "Gil Morlanes el viejo: Nuevo estudio de sus obras góticas", Aragonia Sacra, III, 1988, p. 115122. Nosotros citaremos a partir de esta última edición. El dato que comentamos corresponde al documento 6 de la página 122 . Referencia en el texto en p. 120.

101. M. C. Morte García, «Fernando el Católico y las artes», en: Las artes en Aragón durante el reinado de Fernando el Católico (1479-1516), Zaragoza, 1993,p. 161.

102. Girona, Archivo Diocesano, ms. 14, fol. 90v. Para este manuscrito, véase la nota 113 .

103. Véase la nota 66.

104. J. F. RÀFOls (dir.), Diccionario Biográfico de Artistas de Cataluña, vol. III: H-R Barcelona 1953, ad vocem. 
mano, ocupado quizá ya por entonces por los cadáveres de varios infantes que luego fueron devueltos a ese mismo lugar junto con los restos del de Antequera. De este modo, Fernando el Católico había conseguido lo que perseguía: «collocarles cada huna en su lugar, como quien son y es de razon», dando cabida sobre los arcos a los dos miembros de la dinastía que le importan más: su padre y el monarca que vinculó a los Trastámara a la Corona de Aragón.

Indudablemente, esta intervención del artífice habría quedado registrada en la memoria de la comunidad, y, debido a ello, la obra del sepulcro de Fernando de Antequera, vinculada de algún modo a Morlanes en la medida que lo reflejan las noticias de que disponemos y entendida como coetánea del mausoleo de Juan II, según se infiere por el texto de Prada transcrito anteriormente. Nuestras especulaciones no nos llevan más allá. Tambien es imposible determinar (si el desarrollo de los hechos que proponemos es exacto), el grado de reaprovechamiento de elementos antiguos por parte del escultor aragonés. De todas formas, nos queda por presentar un documento gráfico que quizá aclare algo este extremo, pero, antes, veamos cual fue la génesis del sepulcro de Fernando de Antequera y su periplo posterior.

\section{El sepulcro de Fernando de Antequera y Pere Oller. La intervención de Pere Joan en Poblet: límites y certidumbres}

La advertencia de Alfonso el Magnánimo al abad sobre la inmediata llegada de Pere Oller a Poblet, cuando sólo habían transcurrido unos diez meses desde el óbito de su padre, tenía que ver con el sepulcro monumental previsto ${ }^{105}$. Lo expresa el propio documento. En cambio, que el escultor se hizo cargo del proyecto en firme es, en principio, una suposición, puesto que, salvo esa carta de 1417, no disponemos de otro dato. Está a su favor, sin embargo, la evidencia estilística de los fragmentos conocidos, aunque últimamente se cuestiona la adscripción de todos ellos a un sólo artífice y por tanto a Pere Oller.

Existe otro dato relativo a la actividad del escultor en Poblet que plantea muchas dudas. Se trata de una noticia escueta publicada a principios de siglo por Josep Gudiol, según la cual Oller trabajaba en el sepulcro real en $1442^{106}$. Los veinticinco años que median entre esta fecha y la carta del Magnánimo, al abad, son excesivos para no dudar al respecto, aunque no deba descartarse sin más el posible fundamento de la noticia. Pere Oller estaba activo por entonces en la catedral de Barcelona ${ }^{107}$, donde se conserva el sepulcro de Sança Ximeniç de Foix i de Cabrera $(\dagger 1474)^{108}$, que la

crítica considera suyo ${ }^{109}$. Recordemos que el monumento realizado en vida de la difunta, ocupa un espacio propio en el interior de la catedral de Barcelona: la capilla dedicada a Santa Catalina y Santa Clara, abierta en el lado de la Epístola, en la que el pintor Joan Cabrera doraba la reja de cierre el año $1450^{110}$, signo inequívoco de conclusión de obras. En lo que concierne al sepulcro, se dispone desde antiguo de una noticia que nos lleva a $1436^{111}$. Es importante esta obra en el contexto en el que nos movemos, dado que para la hipotética reconstrucción del frontal real pobletano del que proceden las distintas piezas enumeradas hasta ahora, constituye un referente muy cercano.

Por lo que respecta al sepulcro real en Poblet, diversas fuentes lo dan como concluido en 14321433. Darles crédito supone, por extensión, invalidar la noticia de 1442 aportada por Gudiol, salvo que entendamos que corresponde a la misma fecha y el cambio de número se deba bien a una confusión del historiador o a un error de imprenta. Como se ha señalado con anterioridad, la documentación sobre los panteones reales de Poblet a lo largo del $\mathrm{XV}$ es muy irregular y escasa, lo que contrasta sobremanera con la situación del siglo anterior, y, en sintonía con esta realidad, los registros de Cancillería o la documentación del monasterio no aportan nada nuevo, por ahora, sobre el sepulcro que estudiamos. Últimamente, sin embargo, se ha invocado la presencia de Pere Joan en Poblet el año 1426, para atribuir a su círculo el fragmento más sobresaliente del supuesto sepulcro de Fernando de Antequera: el relieve del «correr les armes», y añadir un nuevo elemento escultórico a los posibles que formaron parte de la decoración del sarcófago.

Esta actividad pobletana era desconocida hasta ahora en la biografía del escultor. Sin embargo, aún habiéndose dado a conocer esta noticia documental, el alcance de su contenido es una incógnita por lo parco de la misma ${ }^{112}$. Por este motivo, ignoramos si puede corresponder a la que localizamos

105. La carta real dice así: «Lo Rey. Venerable abat. Nos trametem aqui en Pere Oller, ymaginaire, portador de la present, per venir reconexer e fer les coses necessaries per lo monument o tomba del cors del senyor rei, pare nostre, de gloriosa memoria. Per ço us pregam que lo y endreçets e li bastregats alguna cosa per les messions que haura a fer entre partir de sa casa, venir aqui a tornar se n, certicants vos que ens en complaurets». Para las referencias véase la nota 3 .

106. El origen de esta noticia, por el momento sin confirmar documentalmente, parece estar en Josep Gudiol. Al menos es quien por primera vez se hace eco de ella: J. Gudiol i Cunill, Nocions de arqueologia sagrada catalana, Vic 1902 , p. 390 y en las suce- sivas ediciones de esta obra. De él debe tomarla: S. SANPERE I Miquel, Los cuatrocentistas catalanes, vol. I, Barcelona, 1906, p. 64. Tambien: A. Palau I Dulcet, Guia de Poblet, Barcelona, 1931, p. 294.

107. J. MAs, «Notes d'esculptors antichs a Catalunya», Boletín de la Real Academia de Buenas Letras de Barcelona, VII (19131914), p. 118. Se le documenta los años 1433-35, 1437-39 y 1443-45.

108. Sobre el personaje: J. M. Sola Morales, «Sancha Ximenes de Cabrera. Iconografía local de la Baja Edad Media", Pyrene, IV (1954), p. 1252-1258. También: El Llibre de Comptes com a font per a l'estudi d'un casal noble de mitjan segle $X V$, edició a cura de J. Andreu i Daufi, J. Caneta Farré, M. A. Serra i Torrent
(Fundació Noguera. Textos i Documents», 27), Barcelona, 1992, p. 25-35.

109. A. Duran Sanpere, Els retaules..., vol. II, p. 29. J. Ainaud, J. Gudiol, F. P. Verrie, La ciudad de Barcelona (Catálogo monumental de España), Madrid, 1947, p. 51, 57. A. Duran Sanpere, J. Ainaud DE LASARTE, Escultura gótica, Madrid, 1956, p. 236.

110. J. Mas, «Notes sobre antichs pintors a Catalunya», Boletín de la Real Academia de Buenas Letras de Barcelona, VI (1911-1912), p. 255.

111. J. Mas, Lo Fossar de la Seu de Barcelona y ses inscripcions funeraries, («Notes históriques del bisbat de Barcelona», VIII), Barcelona, 1911, p. 78. 
nosotros hace unos años en un manuscrito pobletano custodiado en el Archivo Diocesano de Girona, copia de otro anterior del siglo Xvi ${ }^{113}$. Lo dudamos, no obstante, porque se hace difícil deducir una intervención de Pere Joan en el sepulcro que tratamos, a partir de los términos ciertamente imprecisos de esta referencia. Dice así:

[...] llegit he y no he y no se ha hont que en temps del abat Joan Marti se feu lo cor dels monjos en Poblet lany 1430 y que costa demans [?] DCCC florins y en la genealogia de la duquesa de Fer[r]az se llig que un mestre Gommar de Vimbodi obrava les cadires del cor de Poblet y prengue molt gran amistat ab un maestre Pere Joan flamench entallador subtilissim lo qual era anomenat lo gran Pere Joan per la su molta habilitat y havie obrat lo peu del altar major de la Seu de Tarragona y obrave llavors la arcada de les tombes reals qui es devers la sacristia en Poblet. Aquesta obra seria la tomba del rey Ferrando primer la qual es dita damunt que era feta ja temps havie y que los dos archs y sos cobertors consta que ja abans eren fets ab dues sepultures cadascu dells ${ }^{114}$.

Evidentemente, el cronista pobletano hace su afirmación en base a un dato que no es todo lo preciso que sería deseable. Constata la presencia de Pere Joan en el monasterio, interviniendo en la obra del arco situado en el lado de la Epístola, es decir, el que se identifica como contiguo a la sacristía, y de ello deduce la intervención en el sepulcro de Fernando de Antequera. Remarquemos, sin embargo, que esto último es interpretación suya. Por la cronología de los hechos que narra, existe otra explicación alternativa que él, a pesar de disponer de la clave, no contempla, y que tampoco ha tenido presente Manote, cuando explica la presencia de Pere Joan en Poblet en un único sentido: su posible in-

112. La da a conocer: R. M. MANOTE, «Círculo de Pere Joan. Ceremonia de Correr las armas", en: Cathalonia. Arte gótico en los siglos $X I V-X V$, catálogo de exposición, Madrid, 1997, p. 159.

113. Girona, Archivo Diocesano, ms. 14. Las Notas o fragmentos del Archivo Real de Poblet. Copiats dels que trague lo pare fra Marti Marquina, Monjo del Monastir de Santa Maria de Poblet. Morílopare fra Marquina a 16 de abril de 1586 apres de esser estat archiver quaranta anys. Requiescat in pace. Amen. Puede tratarse del Epitome de la Historia del Monasterio de Poblet, obra de este historiador doméstico que se da por perdida. Sobre este autor y su obra desaparecida: A. Altisent, Història..., p. $455-456$ tervención en el sepulcro real.

Según informan los cronistas domésticos, entre 1424 y 1430 , coincidiendo con el abadiato de José Martínez Mengucho, se inició en el monasterio la obra del coro de los monjes. Este proyecto, del que se hacen eco los historiadores pobletanos desde antiguo, atribuyéndolo al abadiato de Miquel Roures (1435-1437), ha sido hasta ahora una simple referencia historiográfica ${ }^{115}$. Que sepamos, nada se ha dicho sobre su artífice, quizá porque las fuentes utilizadas silenciaban tal dato. Sin embargo, el mismo manuscrito que nos proporciona las noticias artísticas inéditas sobre el monasterio que hemos ido presentando, informa también en distintos momentos sobre esta empresa. Las alusiones son contradictorias en lo que atañe a su cronología, puesto que la obra se sitúa sucesivamente en 1424, 1427 o 1430, aunque debe tratarse de la lógica correlación documental que se produce al irse desarrollando un proyecto. Por un lado existe el contrato, y por otro están las ápocas que confirman la actividad posterior a él ${ }^{116}$.

Fue su artífice el valenciano Bartomeu Cervera. Se trata del mismo escultor que ejecutó otros dos coros en Cataluña, ambos en conventos de predicadores: el de la Seu d'Urgell y Vilafranca del Penedès, respectivamente. Mientras se desconoce la cronología del primero, el segundo se documenta en $1458^{117}$. Por lo tanto, la actividad del escultor en Poblet aparece, por el momento, como la primera registrada. Por los datos que aporta el manuscrito pobletano, sabemos que el contrato inicial evaluó la obra en 800 florines y su duración en cuatro años. A pesar de las imprecisiones cronológicas ya subrayadas, lo que parece no plantear dudas es su desarrollo a lo largo del abadiato de Joan Martínez Mengucho y no de Miquel Roures, como se sostiene tradicionalmente ${ }^{118}$.

El párrafo que hemos transcrito en relación con Pere Joan, informa también que en este coro que el
114. Girona, Archivo Diocesano, ms. 14 , fol. $84-84$ v.

115. En el manuscrito del Padre Jaume Fortuny (s. XVII) ya se da esta noticia asociada a dicho abad: J. Guitert i Fontserè, Colecció de manuscrits inèdits..., vol. 4, La Selva del Camp, 1948, p. 102. Remarquemos que Finestres recoge esa atribución y, amparándose en él, también otros historiadores posteriores. Véase: J. Finestres y de Monsalvo, op. cit., vol. III, Cervera, 1756, p. 296. Asimismo: A. Altisent, Història..., p. 375.

116. Existen diversas referencias en el manuscrito pobletano custodiado en Girona, al respecto de este proyecto. Vamos a transcribirlas correlativamente, de acuerdo con su localización en el texto: «Siendo abad de Poblet fray Joan Martinez de Mengucho se hizo el coro de monjes. Començose la obra en el año 1424 al principio de noviembre y havia de esser acabada en los quatro anyos subsiguientes. El maestre principal fue Bartholome Cervera valenciano, costo DCCC florines. Consta todo esto por huna apocha de parte del dicho pretio hecha en el año 1430. El padre Andreu Capdevila que havia conocidos monjes que fueron en el dicho tiempo o muy cerca de aquel desia que le hizo hazer un canonigo de Lerida llamado por sobre nombre Ram y que por esto no ay baculo de abad en los scudos que tiene sino ramos solas como se ve en la parte que mira al altar mayor y al otro fin, cerca de la puerta haz(ia) el coro de frayles. Verdad es que los que estan en la portalada ahunque tienen ramos por divisa principal y tambien tienen adentro baculo abbacial en las mismas piedras leese a 24 de mayo de 1448 huvo por esta tierra gran terremoto y que cayo la dicha portalada de choro de noche en la fiesta de san Urbano de donde parece poderse tomar verismende argumento para dezir que el abad que la torno ha hazer puso en aquellos dos scudos su baculo pues la rehazia a despensas de su monasterio pero dexo los tramos de fuera como principal divisa por reverentia del fundador primero. Don Domingo Ram obispo de Lerida a X de julio de 1421 prometio dar en limosna a Poblet M. florines lo mas presto que pudiese y dise que le ha dado ya la mayor parte dellos y que tiene carta de familiaridad y concierto de venirse retraher y vivir en Poblet. Pretendemos ser que el canonge Ram susodicho que de canonge subio a obispo y ce nombravan como antes Ram» (fols. 28v-29). Hallamos una nueva referencia a este proyecto algo más adelante: «Mestre Bartomeu Cervera valencià, mestre de obra de talla feu lo cor de monjos en Poblet per DCCC florins haviel de acabar en quatre anys los quals començaren a correr lany 1427 dia de Tots Sants. Consta per una apocha de part del dit preu feta l'any 1430. Era abat don frare Joan Martinez Mengucho» (fol. 93 v).

117. Publica estos datos: J. M. Madurell i Marimon, El Arte en la comarca..., p. 11, 103-104, 201202, 281-282. En lo que respecta a su procedencia, por el momento la documentación valenciana no ofrece luz alguna. 
119. J. Finestres y de Monsalvo, op. cit., vol. IV, p. 179-180. A. Altisent, Història..., p. p. 423-424.

120. Mn. S. Capdevila, La Seu de Tarragona, Barcelona, 1935, p. 108. Respecto a Juan, el hermano, quizá pueda identificarse con el Joan Gomar, mercader de Balaguer, que figura en un docu mento de 19 de marzo de 1440 re lacionado con el cobro por parte de Pere Joan de una cantidad adeudada por Dalmau de Mur en relación con el retablo de Tarragona, Lo publica: R. S. JANKE, "Some observations on Pere Johan and the main retable of the Seo of Zaragoza». Miscel-lànea en homenatge a Joan Ainaud de Lasarte, vol. I, Barcelona, 1998, p. 419, nota 11. De tratarse del mismo personaje, habría que considerar este dato, no como algo aislado, sino como parte de las interrelaciones profesionales existentes entre los Gomar y Pere Joan, que expresa su coincidencia temporal y laboral en Poblet y que eran desconocidas hasta ahora por la historiografía.

121. Los documentos relativos a este encargo están fechados el 4 de septiembre, el 29 de octubre y el 18 de noviembre de 1443. Informó acerca del documento relativo a Gomar J. Puiggarí, «Noticias de algunos artistas catalanes inéditos de laEdad Media y del Renacimiento", Memorias de la Real Academia de Buenas Letras de Barcelona, 3 (1880), p 283-284. Lo publicó: S. SANPERE Miquel, Los Cuatrocentistas catalanes I..., p. 238.

122. A su etapa zaragozana se ha atribuido la obra del retablo del palacio episcopal, realizado bajo los auspicios del arzobispo Dalmau de Mur (cf. R. S. JANKE. "The retable of don Dalmau de Mur y Cervelló from the Arch bishop's Palace at Saragossa: A. Documented work by Franci Gomar and Tomas Giner». Metropolitan Museum Journal, 18 (1983), p. 65-83. Una traducción al castellano de este trabajo fue publicada bajo el título: «El retablo de don Dalmau de Mur y Cervelló del Palacio Arzobispal de Zaragoza. Una obra documentada de Francí Gomar y de Tomás Giner», Aragonia Sacra, III (1988), p. 71-90. Nosotros citaremos partir de éste último. A finales de siglo (1490) un Francesc Gomar contrató la obra del pórtico de la puerta de los Apóstoles de la catedral de Lleida (cf. J. LLADONOSA, «El pórtico de los apóstoles de la Seo vieja de Lérida», Ilerda, VI (1946), p. 123-131).

123. Sobre este proyecto: J. M. QuADRADO, España, sus monumentos y arte, su naturaleza e his toria: Aragón, Barcelona, 1886, p. 443-444. Más recientemente: R. S JANKe, El retablo de Don Dalman de Mur..., p. 78-80.

124. Aunque las noticias conocidas sobre este proyecto lo situaban en 1453 (cf. R. FilangieRI DI CANDIDA, «Rassegna critica delle fonti per 1 fuego destruyó en $1575^{119}$, debió de trabajar un miembro de la familia Gomar: «mestre Gommar de Vimbodi obrava les cadires del cor de Poblet». Aunque el nombre no se especifica, por las fechas podría tratarse de Antoni, puesto que está documentado en Tarragona en 1435 junto con su mujer y un hermano llamado Joan del que no se detalla ocupación ${ }^{120}$. Hasta ahora, dentro de la dinastía, el primero documentado profesionalmente era Francí, por su intervención en el retablo de la Verge dels Concellers de Barcelona (1443) ${ }^{121}$. Sin embargo, la actividad de este indeterminado Gomar, en Poblet, la precede, y se trata, además, de la obra de un coro, un género de proyecto para el que serán reclamados ambos hermanos en distintos momentos, y más adelante un hijo de Francí, llamado tambien Antoni. Recordemos, en este sentido, la responsabilidad de los miembros de esta dinastía, junto a otras ${ }^{122}$, en la obra de los coros del Salvador de Zaragoza (desde 1444 ?) ${ }^{123}$, del Castelnuovo de Nápoles (1451) ${ }^{124}$ y de la catedral de Tarragona (desde 1478) ${ }^{125}$. En Poblet, por lo que parece desprenderse de la escueta noticia, Antoni debía trabajar a las órdenes de Bartomeu Cervera.

La razón de registrar a Pere Joan en relación con el arco de los sepulcros reales emplazados en el lado de la epístola, puede explicarse perfectamente como algo derivado de este proyecto. A diferencia del actual, este coro ocupaba el espacio intermedio entre ambos arcos reales, y probablemente su asentamiento debió obligar a algún reajuste. Cuando un incendio lo destruya avanzado el siglo XVI, se decidirá retrasar el nuevo, un tramo, ubicándolo más cerca de la entrada dejando libre el espacio que ocupaba el antiguo ${ }^{126}$. De todo ello se deduce que el coro existente hoy en día en Poblet, mantiene un emplazamiento que no se fijó hasta avanzado el siglo XVI.

Pere Joan trabajó en Poblet en 1426 y tal hecho parece incontrovertible, tanto a partir de la información que trasmite el historiador doméstico al que nosotros hemos recurrido, como en base a la noticia invocada por Manote. De este hecho, sin embargo, no parece poderse deducir por el momento que él o alguno de sus colaboradores haya intervenido en los sepulcros reales, entre otros motivos porque aquel mismo año el escultor asumía su primer compromiso laboral de envergadura (el retablo de la catedral de Tarragona) del que surgirá el primer equipo de colaboradores conocido ${ }^{127}$. La «interpretación» que hace el cronista pobletano del dato histórico es arriesgada, puesto que no tiene en cuenta el desarrollo contemporáneo de otros proyectos artísticos en la iglesia de Poblet que habrían podido justificar una intervención en el arco real del lado sur ${ }^{128}$. Nos lo parece igualmente, en base a la simple constatación de su presencia en el monasterio, atribuir al círculo de Pere Joan el relieve del «correr les armes» del sepulcro real. Aun- que adscrito en trabajos pioneros al ambiente de este escultor (incluso se invocó para él, en algun caso, el nombre de Guillem de la Mota) ${ }^{129}$, desde un cierto momento la historiografía lo ha reconocido como obra de Pere Oller. Han influido en ello tanto las afinidades estilísticas que descubre respecto a la restante producción del artífice, como su indudable proximidad a los elementos dispersos conocidos del sepulcro real.

Precisamente María Rosa Manote, dos años antes de pronunciarse a favor de esta algo sorprendente atribución, lo había adscrito a Pere Oller ${ }^{130}$. $\mathrm{Su}$ posicionamiento actual supone retomar una vieja atribución, ignorando que aquéllos que la habían suscrito desconocían la existencia del conjunto de plorantes que, con el polémico relieve, parecen haber decorado el sarcófago real. Ya que la observación de estas piezas pone de manifiesto la existencia de parentescos estilísticos tan estrechos entre ellas, defender una sola autoría para su conjunto es del todo coherente. Lo es en el plano tipológico y en el iconográfico. Ciertamente, si contemplamos todos los plorantes y el relieve como resultado de un proyecto unitario, el referente que es obligado invocar para reubicar en parte las piezas de este puzzle escultórico es el sepulcro de Sança Ximeniç de Foix i Cabrera, en la catedral de Barcelona ${ }^{131}$. En su frontal, seis plañideras de pie y aisladas dentro de espacios independientes, se distribuyen a ambos lados de un relieve central de formato cuadrado, donde campea una escena que parece evocar a la dama destinataria del monumento practicando la devoción privada junto con sus doncellas ${ }^{132}$.

La presencia de este relieve en medio del frontal constituye una rareza en el contexto catalán contemporáneo, pero la razón que la justifica es la misma que podemos invocar para el caso pobletano. En un mausoleo exento, como sucede con el confeccionado por Oller para el obispo Berenguer d'Anglesola, en la catedral de Girona ${ }^{133}$, el emplazamiento natural de una lastra de ese formato sería bien la zona de la cabecera o la de los pies del sarcófago. Sin embargo, en el caso del de la catedral de Barcelona esto no era posible, porque el monumento funerario está bajo arcosolio, embutido en la pared. Por tanto, lo que se ha hecho ha sido desplazar a la zona frontal de la caja uno de sus elementos más sobresalientes, tanto por formato como por iconografía.

En el caso del sepulcro real de Poblet, el relieve del «correr les armes» tampoco hubiera cabido ni a los pies ni a la cabecera del sarcófago, simplemente porque la primera no existe y la segunda no era visible ${ }^{134}$. Recordemos, además, que una de las noticias sobre su venta, hablaba de él en estos términos; "procedente, al parecer, de la parte delantera de un sepulcro de Poblet» ${ }^{135}$. Podemos dar crédito o no a esta observación, pero en lo que 
concierne a la organización del frontal pobletano, en principio, todo parece apoyar esta propuesta de reconstrucción que sostenemos, en especial el posible paralelo que ofrece el sepulcro de la catedral de Barcelona. Se trataría, pues, de plantearla con el relieve del «correr les armes» en su centro.

Lamentablemente, el estado en el que llegaron al siglo xx los sepulcros reales y la inexistencia de descripciones más precisas impide ir más allá, puesto que las noticias antiguas sobre los mausoleos son insuficientes para evaluar aspectos de su tipología o aquéllos que atañen a la distribución de los temas iconográficos en la ornamentación de los frontales. Esta zona parece haber interesado menos que los detalles de las figuras yacentes que presidían las cubiertas. Aún así, existen coincidencias entre diversas fuentes a la hora de subrayar la presencia de escultura menuda en esa zona. Es el caso de Finestres, que la describe en estos términos: «Son todos dichos seis sepulcros de fino alabastro labrados por uno y otro lado con mucha imaginería pequeña, que retratan las Victorias de los mismos Reyes, y la pompa funeral de sus Entierros. Y en lo alto de los sepulcros, sobre la cubierta de las tumbas, se representan los propios reyes en estatuas también de alabastro tendidas, unas con vestido real, otras con el habito en que fueron sepultadas» ${ }^{136}$.

Indudablemente, el historiador pobletano constituye un testimonio ocular mucho más fiable que Piferrer o Laborde ${ }^{137}$, aunque parece claro que ambos lo siguen muy de cerca en este punto. El pri-

storia di Castelnuovo", Archivo Storico per le province napoletane, II (1938) p. 43), un dato aparecido recientemente permite corregir esa fecha. Antoni Gomar ya se hallaba en Nápoles, trabajando en el coro del Castelnuovo, en 1415 (cf. G. LlomparT, «Miscelánea de arquitectura y plástica sacra mallorquina (siglos XIIIXVI)», Analecta Sacra Tarraconensia, 46 (1973), p. 93, nota 30 Este proyecto italiano se desarrolló, por tanto, paralelamente al coro de Zaragoza, que no se concluyó hasta 1453 (véanse las notas 122-123).

125. J. BLANCH, Arxiepiscopolog de la Santa Església Metropolitana i primada de Tarragona, vol. II, Tarragona, 1985, p. 119-120. P. Piferrer, F. Parcerisa, Recuerdos y Bellezas..., vol. I, Barcelona, 1839 , p. 236; Mn. S. CAPDEVILA, op. cit., p. 18-19. I Companys, N. MonTARDit, «El treball de la pedra i la fusta a través dels autors esmentats al Llibre de l'Obra de la Seu de Tarragona (1423-1499)», en: Recull Pan Monguió i Segura (1865-1956), Tarragona, 1988, p. 17-29, 33.

126. Hablan de la nueva localización y del contexto en el que se llevó a cabo, distintos cronistas domésticos. Entre ellos fra Martí Marquina (cf mero, parece haber redactado el capítulo dedicado a Poblet del primer volumen de los Recuerdos y Bellezas de España, basándose en los datos recopilados con anterioridad a la exclaustración:

\section{[...] las bellisimas urnas góticas que son tres en} cada panteon, separadas por pilares del mismo estilo. Guarnece todas sus caras una galeria de pequeños nichos en que, como se suele ver en los mejores sepulcros del género, hay tristes y graves barones, cubiertos con sendas y holgadas túnicas, por debajo de cuyos capuces asoman sus rostros meditabundos y doloridos, y ocupan el restante espacio las batallas, las acciones memorables y pompas funerales de los reyes, en relieve harto magníficos y notables por su espresión y delicadeza. A tanta riqueza de escultura agrégase el brillo del azul y oro, que reluce en los espacios que ellos no llenan, sobre los vidrios, de que para ornato de las más señaladas urnas acostumbraba valerse el arte de la edad media ${ }^{138}$.

Junto a estas noticias existe otro género de información que, aunque en algún caso se ha desestimado, abre a nuestro juicio una vía de acercamiento que no sería prudente marginar. Nos referimos al conocido grabado del Voyage pittoresque de Alexandre Laborde que ilustra, entre otros, el capítulo consagrado a Poblet (figura 9) y a la litografía publicada en el segundo volumen dedicado a
J. Gutterti Fontserì, Collecció de Manuscrits inèdits..., vol. I, p. 43, 45-47) y Jaume Fortuny (ibídem, vol. 4, p. 44-45. Ibídem, vol. 6, p. $52,174-175)$.

127. El acta capitular de 8 de marzo de 1426 informa de los términos del convenio entre el artista y los miembros de la iglesia tarraconense. Lo publica con los restantes documentos relativos al proyecto: Mn. S. CAPDEVILA, op. cit., p. 26-27 y s.

128. De haber afectado la obra del coro al arco real, como creemos, indudablemente quien habría corrido con los gastos de restauración habría sido el rey, y, por tanto, habría constancia de ello en los registros de Cancillería.

129. H. Stegmann, D. Angulo, $L a$ escultura en Occidente, BarcelonaBuenos Aires, 1926, p. 12. E. ToRMO, La escultura española en la Edad Media, Madrid, 1926, p. 49.

130. Véanse los argumentos a favor de Oller: M.R. MANOTE, Correr les armes..., p. 103-104 «Però ¿pot ser atribuïda aquesta obra a Pere Oller? A judici meu, una tal atribució té fundades possibilitats si hom té en compte, a mès del que s'ha exposat quant a la cronologia, el cànon de les figures, el preciosisme i la minuciositat de la talla i l'estructura i composició dels elements arquitectònics del relleu parisenc, semblants a les d'alguns dels que emmarquen els relleus del retaule major de la catedral de Vic, tallat en alabastre per Pere Oller el 1420 [...]».. Sobre la opinión actual: ídem Círculo de Pere Joan..., p. 159. En esta ocasión, ha modificado la atribución del relieve, a la par que la de una figura femenina de alabastro que en el trabajo anterior tambien atribuía a Oller (incomprensiblemente, puesto que se trata de una obra muy clara de Pere Joan) y al mismo sepulcro real pobletano del que procede la lastra del «Correr les armes». Para nosotros la procedencia apuntada para esta figura exenta es más que dudosa. No se aportan datos históricos que lo apoyen, ni se llega a especificar el papel que se supone desempeñó tipológica o iconográficamente en el contexto del sepulcro real. Se presenta como procedente del sepulcro, sin más. En nuestra opinión, solo se podría haber propuesto una posibilidad al respecto: su pertenencia a la zona de los montantes que adornan los sepulcros reales, aunque, por las características de la figura (observemos que ni siquiera su indumentaria tiene que ver con la propia del duelo), tal origen parece bastante improbable. Por el contrario, nos parece que su adscripción indudable a Pere Joan abre el camino a otras posibilidades mucho más coherentes en relación con la obra del escultor. El bancal del retablo de la catedral de Tarragona, por ejemplo, constituye un punto de referencia extremadamente elocuente: cada una de las escenas de la leyenda hagiográfica de la mártir está flanqueada por pequeñas figuras de santas (santa Inés, por ejemplo), directamente parangonables con la figura de la actual colección Barrachina, aunque la torsión corporal de ésta última quizá se acomode mejor con la propia de una Virgen de la Anunciación, donde el brazo desaparecido correspondería, además, al habitual gesto de sorpresa.

131. Ya lo hicimos en su momento (F. Español, Plorants del sepulcre de Ferran...), pero esta propuesta, que nos sigue pareciendo tan viable como entonces, porque se basta en la búsqueda y cotejo de posibles paralelos contemporáneos, ni siquiera ha sido objeto de discusión o de aceptación por parte de Manote, cuando, según mis conocimientos, es la primera y única que se ha planteado hasta hoy.
132. Sobre el desarrollo de la devoción privada en este contexto, véase a propósito del rezo de las horas en común, los comentarios de:J. YARZA LUACES, «María de Navarra y la ilustración del Libro de Horas de la Biblioteca Nazionale Marciana», en: V.V.A.A., Libro de Horas de la reina María de Navarra, Barcelona, 1996, p. 106 y s.

133. Véase al respecto en este mismo volumen, la nota que dedica al hallazgo del contrato del sepulcro Joan Valero.

134. Los sarcófagos están adosados unos a otros, a excepción de los situados en los extremos que dejan libre una de sus caras menores. Sin embargo, como los arcos reales ocupan la zona de intercolumnios del crucero, estos lados exentos de los sarcófagos quedan también ocultos por los pilares.

135. Véase el texto que corresponde a la nota 33 .

136. J. Finestres y de MonsalVo, op. cit..., vol. I, p. 255.

137. Sobre los comentarios de Laborde (op. cit.,) véase p. 207214 de la traducción catalana.

138. F. Parcerisas, P. Piferre, $R e-$ cuerdos y Bellezas..., vol. I, p. 255. 


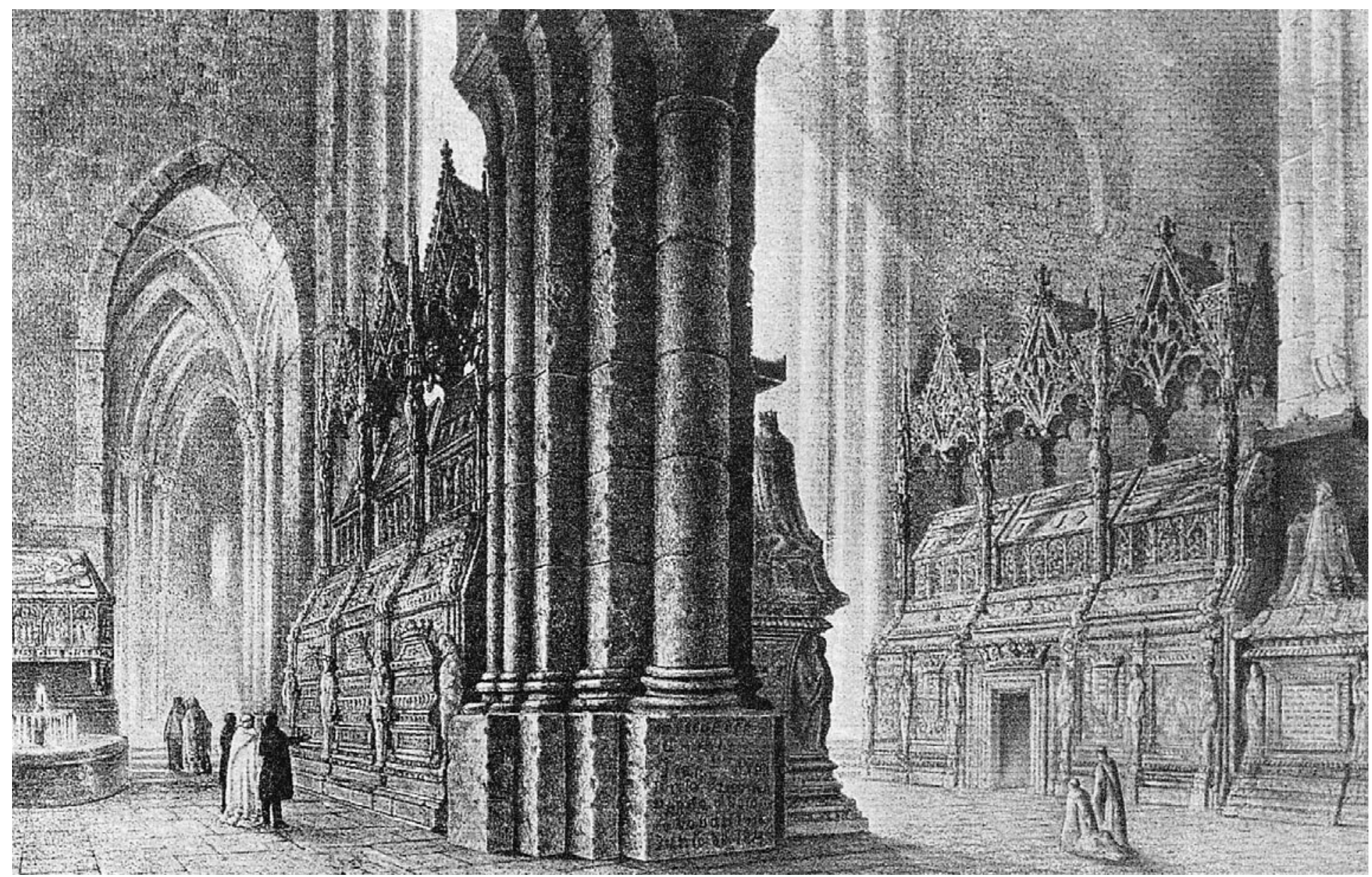

Figura 10.

Litografía de Francesc Parcerisa para el segundo volumen dedicado a Catalunya de los Recuerdos y Bellezas de España.

139. F. Parcerisas, F. Pi MARGALl, Recuerdos..., vol. II, p. 292 , nota 1 .

140. Se publican algunos de estos dibujos preparatorios de las láminas de Cataluña, Valencia y Baleares, conservados en Barcelona, en el segundo volumen de la traducción catalana del Voyage pittoresque (véase la nota 75 ). La correspondencia entre la lámina LXXVI y dos de estos dibujos, la defienden los historiadores que han preparado esta edición (cf. vol. II, dibujo 30, p. 258, referencias en p. 257)

141. En ellas se adoptó una doble solución repetida en ambos arcos. Por un lado, en la fachada orientada hacia la nave mayor de la iglesia, alternaban escudos de gran formato, con relieves rectangulares de similar proporción que acogían escenas historiadas; todo ello flanqueado por figuras, modo de cariátides. En la fachada opuesta se representaron tre sarcófagos en alto relieve soste nidos por parejas de leones. Por tanto, el grabado que analizamos corresponde a la fachada contigua a la iglesia del arco norte.
Cataluña de los Recuerdos y Bellezas de España (figura 10). Ésta última, realizada desde el extremo noroccidental de la iglesia, muestra una imagen global de los arcos reales en la que se observan aspectos generales de los mismos. Todo ello (desde los baldaquinos hasta la distribución de la ornamentación en los frontales) escasamente fiable, puesto que, como advierte el mismo texto que la acompaña, se trata de una recreación posterior a la destrucción: «Algunos restos que quedaban aún de estos sepulcros en la época en que lo visitó el litógrafo y la detallada descripción que de ellos hizo Finestres en su "Historia de Poblet" han permitido aun darlos restaurados a nuestros lectores» ${ }^{139}$.

Es más detallada la visión que proporciona el grabado de Laborde, aunque su confrontación con los dibujos preparatorios que se han conservado, evidencia hasta que punto se han simplificado ciertos detalles. Ofrece una panorámica del arco situado en el lado del evangelio, y de su fachada sur contigua a la nave central de la iglesia, pero la observación atenta del dibujo preparatorio revela particularismos decorativos de los frontales que se han eliminado en la lámina definitiva ${ }^{140}$. Un somero análisis lo pone de relieve: donde en el original se advierten relieves de formato cuadrado con ángeles tenentes de escudos y grupos de personajes bajo una arquería seguida, en la lámina final la simplificación lo ha reducido todo a una serie de figuras aisladas bajo simples arcos ciegos. Que se trata del mismo ángulo y del mismo arco lo confirma la decoración del cierre de la zona baja que corresponde a las cámaras sepulcrales de los Cardona ${ }^{141}$. No hay duda. Además, en el extremo derecho, se advierten los escalones que salvan el desnivel existente entre la nave de la iglesia y el presbiterio y lo que corresponde a uno de los altares relicario que bajo los auspicios de Pedro Antonio de Aragón realizaron los hermanos Grau de Manresa, y que aún flanquean el altar mayor de Damián Forment ${ }^{142}$. Advertida la libertad con la que el grabador utiliza el dibujo original, del que respeta el diseño del baldaquino, la disposición de los yacentes y la ornamentación de la zona inferior al registro que corresponde al frontal de los sepulcros, pero en absoluto el desarrollo ornamental de esta última zona, es obligado centrarse en los dibujos preparatorios para avanzar en nuestros propósitos.

Observando uno de ellos en donde se ofrece una panorámica general del arco opuesto, pero no des- 


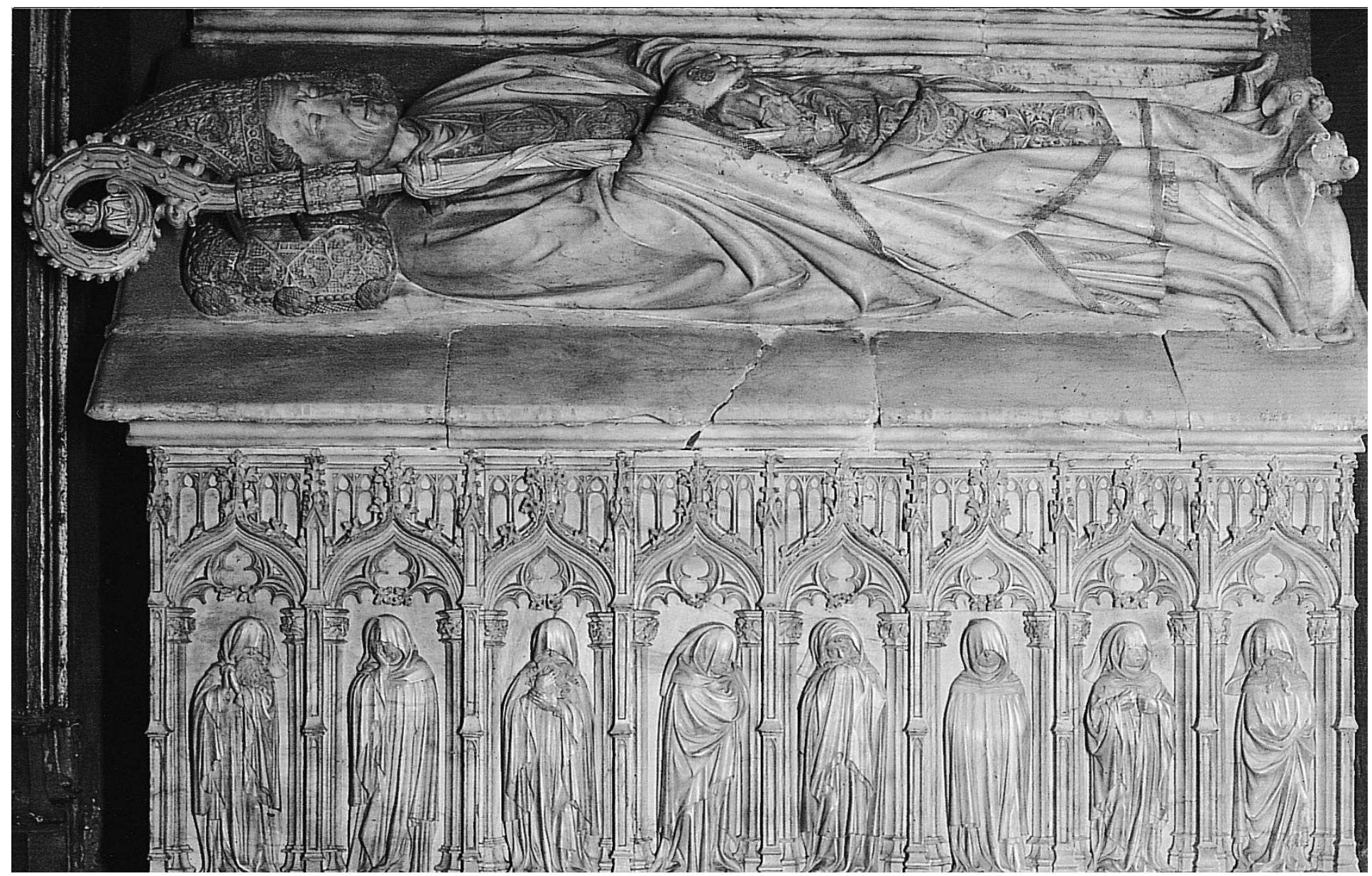

Figura 11.

Antoni Canet. Sepulcro del obispo Ramon Escales en la catedral de Barcelona.

de la nave central sino desde la lateral ${ }^{143}$, se advierte que probablemente el grabador se inspiró en él para adoptar la solución simplificada que muestran los frontales del grabado definitivo. La fórmula de las figuras aisladas bajo arcos, se ha tomado de la que al parecer adornó realmente los frontales de los sepulcros que corresponden a Alfonso el Casto y a Juan I. En cambio, el del extremo occidental, donde en 1499 se inhumó a Juan II y a Juana Enríquez con su hija, muestra una serie de personajes componiendo lo que parece un séquito fúnebre, sin ningún género de elemento arquitectónico separador entre ellos, ni siquiera en la zona superior (figura 12). Quizás haya que interpretar, alusivos a esta zona del sepulcro, los comentarios de algunos cronistas pobletanos que, al hablar del sepulcro de Juan II, remarcan el carácter inusual de su ornamentación ${ }^{144}$.

No se trata de una fórmula muy corriente, aunque hallamos un posible precedente trecentista en el frontal del sepulcro del obispo Arnau de Montrodon en la catedral de Girona ${ }^{145}$. El análisis pormenorizado del dibujo permite entrever que corresponde a un cortejo integrado por unos dieciséis personajes, todos vestidos con gramallas, avanzando ordenadamente en una misma dirección: el presbiterio de la iglesia. No se hace difícil reconocer, en la figura situada en el extremo derecho que abre la procesión, estrechas coincidencias con el plorante de la antigua colección Terez (figura 7), cuyo cuerpo envuelto por la túnica y en posición de contrapposto resulta tan característico. Tampoco es difícil apreciar lejanos parentescos en lo relativo a su disposición entre las dos figuras custodiadas ahora en el monasterio de Poblet (figura 4) y las situadas en segundo y tercer lugar, desde la izquierda. Dada la configuración general de la escena - sin elementos de separación entre los plorantes- también podría proceder de este ámbito el plorante de la antigua colección Junyent, ahora en Nueva York. Estas constataciones, sin embargo, plantean un grave problema: el de explicar como atribuir a un escultor de finales del siglo $\mathrm{XV}$ unas esculturas adscritas estilísticamente al gótico internacional. Indudablemente se trata de una cuestión difícil de solventar, salvo que invoquemos la peripecia algo rocambolesca que hemos defendido con anterioridad para los mausoleos reales. En este caso, sería perfectamente sostenible que los cambios introducidos en el destino de los espacios
143. Nosotros, en la figura 12 , publicamos un detalle del mismo. Para su reproducción íntegra, véase la página 258 del apéndice a la traducción catalana parcial del Voyage Pittoresque que citamos en la nota 75 .

144. En el manuscrito de Vicenç Prada leemos: «hasta que el Rey catholico, a sus expensas, hizo fabricar los dos sepulcros del Rey Don Fernando el $1^{\circ}$ y del Rey Don Juan el $2^{\circ}$ como hoy se ven [...] y concluidos fue colocado este Rey en 4 de mayo, año 1499, con su muger la Reyna $\mathrm{D}^{\mathrm{a}}$ Juana y una hija de ambos [...] en el sepulcro mas cercano al organo, muy diferente en la imagineria a los otros [...]», en: R. DEL ARCO, op. cit., p. 603.

145. En este sepulcro, bajo una galeria corrida de arcos góticos, se sitúan un total de diez personajes. En el centro se halla el habitual oficiante flanqueado por tres acólitos y, a la izquierda del grupo, tres figuras dolientes femeninas y, a la derecha, otras tres masculinas. 
146. Respecto a la pertenencia de todos los relieves insertados actualmente en el frontal a la obra del sepulcro primitivo, queremos manifestar nuestras dudas. De los cuatro, tres de ellos manifiestan un similar nivel de calidad y una proximidad estilística indudables. El cuarto creo que se distancia notablemente de ellos por ambos conceptos en igual medida. Se trata del situado en segundo lugar, desde la izquierda, que muestra al oficiante flanqueado por sus acólitos. Es tal el contraste existente, que entendemos más que razonable cuestionar su pertenencia primitiva al sepulcro de Juan II. En cambio, podría haber formado parte del mismo, un relieve con esa misma temática que coincide en formato, material y estilo con los restantes, perteneciente al Museo Marès de Barcelona. Apunté ya este posible origen pobletano en el estudio de esta pieza: F. Español BerTran, «Atribuïble a Gil Morlanes el Vell. Relleu Funerari», en: F. EsPAÑol, J. Yarza (dir.), Catàleg d'escultura i pintura medievals, ( «Fons del Museu Frederic Marès», 1), Barcelona, 1991, p. 192-193. Ficha publicada de nuevo en: Catalunya Medieval, catálogo de exposición, Barcelona, 1992, p. 238-239. Aunque en ese momento para proponer ese origen me basé en cuestiones puramente tipológicas, estilísticas, de material y de formato, dispongo ahora de un dato que parece confirmar esa procedencia. Se trata de una antigua fotografía del relieve, existente en el archivo fotográfico del Servei del Patrimoni de la Diputación de Barcelona, en cuyo dorso aparece señalado en número de clixé: «5.298», el origen del mismo "Clixé Golferichs», la fecha «1906» y se da como correspondiente a «Poblet, Conca de Barberà». Sobre los trabajos de restauración y reintegración llevados a cabo en los años cuarenta, véase: Las es tatuas funerarias de los Reyes de Aragón, catálogo de exposición, Barcelona, 1946.

147. Las descripciones antiguas hablan de la existencia de tres figuras yacentes sobre los sepulcros: Dos (masculina y femenina) en hábito diaconal en la zona contigua a la nave mayor, una tercera en la zona inmediata al dormitorio de «un rey armado de todas sus armas», según el manuscrito de Vicente Prada. Ésta última es la que reproduce supuestamente: V. POLERO, Estátuas tumulares de personajes españoles de los siglos XIII al XVII, Madrid, 1903, p. 4546 y lámina. De este yacente que, como el mismo Poleró reconoce, ya vio muy estropeado al visitar Poblet, en la actualidad no se conserva ningún testimonio. Dadas las reservas manifestadas a propósito de su correcta atribución por historiadores posteriores, hemos preferido dejar de lado todo lo relativo a esta figura en nuestro estudio.

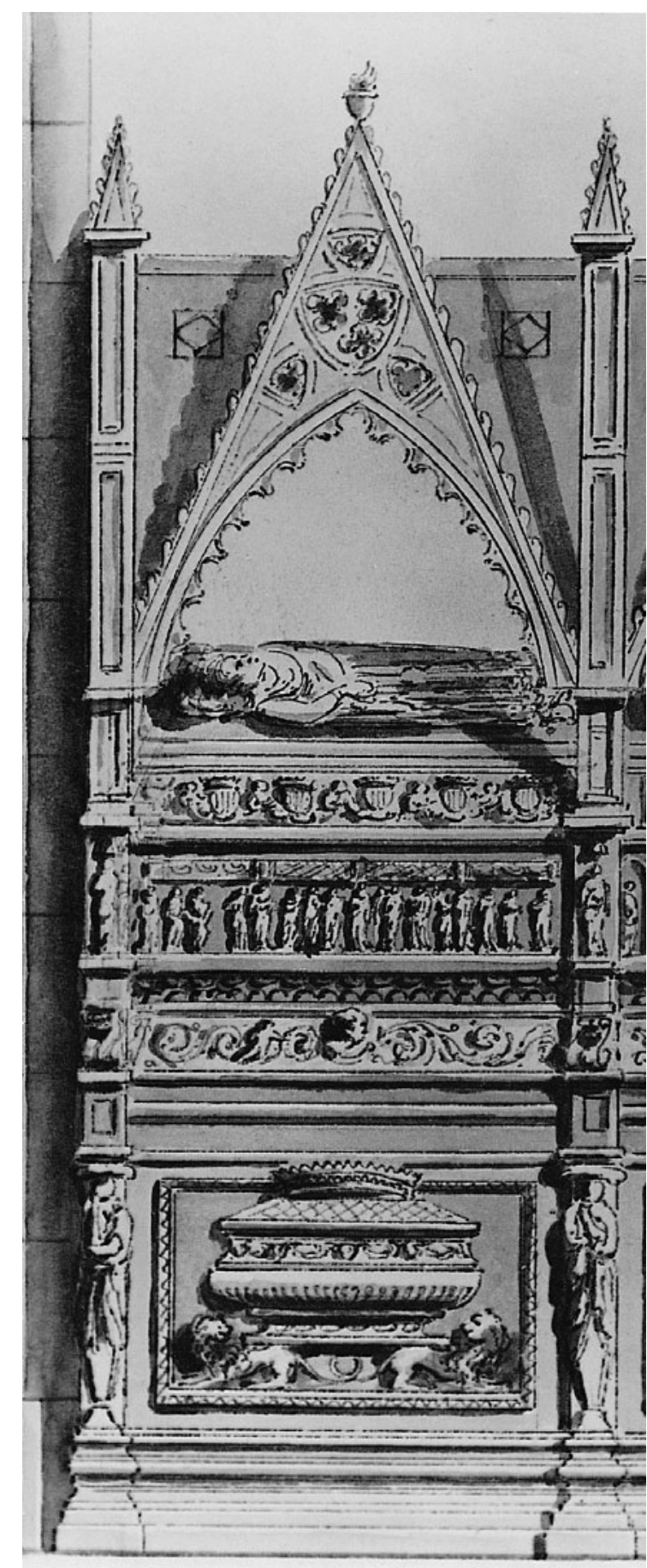

Figura 12

Dibujo preparatorio para el grabado de los panteones reales de Poblet del Voyage Pittoresque, de Alexandre Laborde. Barcelona, Museu Nacional d'Art de Catalunya. Sepulcro de Juan II, fachada meridional. de inhumación existentes en el extremo occidental de los arcos a finales del siglo xv, hubiera implicado una labor de mantenimiento, a la par que otra de renovación de la escultura que los decoraba. En este caso específico, puesto que se trataba de la zona más secundaria del mausoleo ya que era la que estaba encarada hacia la sacristía, el frontal sur del primitivo sepulcro de Fernando de Antequera habría sido mantenido in situ por Gil Morlanes, pasando a formar parte del de Juan II. El escultor habría labrado, pues, sólo las dos figuras yacentes reales y el frontal contiguo a la nave mayor de la iglesia, respetando la primitiva fachada meridional del mismo, obra antigua de Pere Oller. Los relieves reintegrados al frontal norte de ese mausoleo durante la recreación del panteón real realizada en los años cuarenta por Frederic Marès, serían parte de lo ejecutado por Morlanes ${ }^{146}$.

Por lo que respecta al «nuevo» sepulcro ubicado en el extremo occidental del arco norte, destinado en 1499 a Fernando de Antequera, es perfectamente visible en uno de los dibujos preparatorios de la lámina publicada en el Voyage pittoresque de Laborde. Lo son menos los cinco relieves que decoran su frontal, encarado hacia la nave mayor. Observándolos con atención, se aprecia, sin embargo, un detalle de cierta trascendencia. Del conjunto, los dos situados en los extremos ostentan ángeles tenentes de escudos y los tres centrales, grupos de personajes. En el cuarto, la proporción de estas figuras es sensiblemente menor que en los tres restantes. Puede que no podamos comprobar nunca este extremo, pero una evidencia de este tipo apunta por lo general en una dirección: piezas de distinta procedencia ensambladas facticiamente. Sin duda, de ser así, se trataría de un argumento a favor de la hipótesis que hemos estado defendiendo hasta ahora.

Si se procedió al desmantelamiento parcial del sepulcro de Fernando de Antequera, es posible que alguno de los fragmentos extraídos se integrara en el nuevo, con toda seguridad los yacentes, por ejemplo ${ }^{147}$. Quizá el relieve del «correr les armes» siguió esa suerte, aunque hay que reconocer que el dibujo que nos sirve de guía es lo bastante impreciso para impedir llegar a conclusiones definitivas en este punto. Sin embargo, aún dejando en el aire algunos aspectos que le conciernen, creo que de lo aportado hasta ahora se pueden extraer algunas conclusiones.

\section{Reflexiones finales}

En las páginas precedentes hemos evaluado los datos históricos relativos al sepulcro de Fernando de Antequera y, en general, a los mausoleos reales pobletanos durante el siglo xv, unos conocidos, otros inéditos hasta ahora. Asimismo, nos hemos hecho eco de la aportación al tema de la historiografía pobletana desde el siglo xvi, y he- 
mos ido planteando interpretaciones posibles a las incógnitas que ha suscitado su estudio a quienes nos han precedido en este empeño.

En este análisis de los hechos, no se puede pasar por alto que existe una memoria antigua a favor del origen pobletano de ciertos fragmentos escultóricos, en alabastro, dispersos en la actualidad por varias colecciones, que datan de comienzos del siglo xv y coinciden con el estilo de Pere Oller. Algunos permanecieron en manos de sus propietarios desde el mismo momento del expolio, y debemos partir de esa certeza al recapitular sobre la posible historia del monumento funerario. Estaría en esta situación el relieve del «correr les armes», una pieza de origen pobletano como lo confirma la reclamación de la Comisión Provincial de Monumentos a su poseedor, y ya en manos particulares menos de diez años después de decretarse la Desamortización de los bienes eclesiásticos.

De los plorantes atribuidos al mismo sepulcro, indudablemente algunos lo han sido desde antiguo, y sus primeros propietarios conocidos pueden haber tenido conocimiento directo del autor o del período de extracción de las figuras. Por eso es tan importante, no solo que conste su origen pobletano en su venta posterior ${ }^{148}$, sino que coincidan los materiales, las medidas y el estilo de todos ellos. Así, el conjunto de figuras censadas hasta hoy son de alabastro ${ }^{149}$, apoyan sobre un discreto zócalo y la altura de unas y otras oscila escasamente ${ }^{150}$. Del total, sin embargo, las dos que Duran y Sanpere devolvió a su disposición originaria (una de ellas por unos años parte de la colección Batlló, la otra reunida con las restantes piezas pobletanas en el Museo Provincial de Tarragona por Hernández Sanahuja) se hallan entre las más fiables, junto con los dos plorantes presumiblemente originarios de la colección Junyent (ahora en el Metropolitan Museum de Nueva York y en el Museo de Lawrence, Kansas, respectivamente). Todos estos fragmentos, revelan el estilo de Pere Oller, como también lo hace en nuestra opinión el relieve del «correr les armes». Hallamos los mismos recursos escultóricos en el plorante de la antigua colección Terez, en el que se custodia ahora en Chicago, y los descubrimos, asimismo, en el fragmento del Museo de la Obra en Poblet, e incluso en el plorante en paradero desconocido que dibujó Milà i Fontanals. Se trata, en todos los casos, de figuras de pequeña complexión que adquieren cierta entidad volumétrica gracias a las túnicas holgadas que visten, salvo en el caso de los jinetes del relieve del «correr les armes», a quienes el arnés pone de manifiesto lo escuálido de su cuerpo - en igual medida que lo hace en las figuras de San Miguel y San Hipólito del retablo de Vic- ${ }^{151}$. Precisamen- maño de manos y cabezas, un género de desproporción que es común a todos los fragmentos atribuidos a este sepulcro real y que caracteriza el estilo de Oller en su obra más emblemática: el retablo de Vic. La comunidad estilística de todos estos fragmentos también se evidencia en el tratamiento de los rostros. En los ojos y en la boca es donde el artista ha plasmado el rictus de dolor. Basta comparar las cabezas de los jinetes del relieve, particularmente el del centro y el situado a su derecha, con la cabeza del Museo de la Obra de Poblet y, aunque menos expresivas, la del plorante del Metropolitan y la del perteneciente a la antigua colección Terez, para percibir que se trata en todos los casos del producto de un mismo artista, con recetas alternativas, pero próximas entre sí. Otro género de estilema lo descubrimos en la resolución de las partes bajas de las figuras, donde las túnicas se abren en abanico debido a la peculiar posición de las piernas, generándose un plegado muy caprichoso sobre los pies, que está totalmente en sintonía con los dictados del gótico internacional. Todos estos rasgos aproximan la totalidad de los fragmentos analizados en la obra de Pere Oller y descartan a Pere Joan, o a algun hipotético seguidor suyo, como artífices del elemento más relevante del conjunto. No hay necesidad de acudir a ellos, ni para justificar cuestiones de orden estilístico, ni compositivo. Respecto a lo primero, acabamos de manifestar nuestras razones, pero como argumento favorable a dicho posicionamiento podríamos añadir un dato más: el contraste entre la robustez corpórea que transmite el san Jorge del medallón de Pere Joan para el Palacio de la Generalitat que en toda esta controversia atribucionista acaba siendo para unos clave en un sentido y para nosotros clave en el sentido contrario. Pere Joan esculpe cuerpos más robustos que Oller y la comparación de los jinetes del relieve funerario y el san Jorge barcelonés evidencia la distancia que media entre unos y otro: huesos menudos en los primeros, huesos grandes y musculatura abundante en el segundo. Debemos volver a este mismo relieve barcelonés en lo concerniente a la composición del pobletano, puesto que creemos que con relación a él se ha sobrevalorado en exceso el peso del primero ${ }^{152}$. Ambos son deudores, en igual medida, de una fórmula ya antigua por entonces en el campo de la sigilografía ${ }^{153}$, que uno y otro adaptan al campo escultórico con mayor o menor fortuna. No se olvide, además, a tenor de las descripciones de los sepulcros reales conocidas — «con mucha imaginería pequeña, que retratan las Victorias de los mismos Reyes, y la pompa funeral de sus Entierros...», leemos-,que en Poblet puede haber habido relieves alusivos al «correr les armes» ya en los mausoleos del siglo XIV ${ }^{154}$. Una serie de testimonios prueban su difusión en el área
148. Aunque podría negarse valor a este hecho, dadas las circunstancias del mercado anticuario catalán del paso del siglo XIX al $\mathrm{xx}$, en el que señalar como procedentes de Poblet ciertas obras incrementaba su valor económico, creemos que por una simple cuestión estadística esto podría aceptarse como posible para una parte de los fragmentos, pero no para su conjunto. Por lo tanto, en un caso extremo, habría que reconocer que el origen pobletano de ciertas figuras podría ser apócrifo, pero no el de todas.

149. Quizá, en un futuro, un análisis petrográfico ayude a descartar dudas sobre la pertenencia de todos estos fragmentos a un solo sepulcro. Del alabastro usado en los panteones reales de Poblet se conocen diversos orígenes: el autóctono de la Conca de Barberà; el de Beuda, en Girona, y el de Gelsa, en Zaragoza. De tratarse, como cremos, del de Fernando de Antequera, probablemente sería alabastro de Beuda, cantera a la que acudió Oller en otras ocasiones, como en el caso del retablo de Vic.

150. Miden todos unos 37 centímetros de altura, mientras que la altura total del relieve del «correr les armes» (incluida la arquería superior) es de 64 centímetros.

151. La reproducción en: A. DuRAN I SANPERE, Els retaules..., vol. II, figuras de la lámina 17.

152. Sobre esta cuestión: M.R. MANOTE, Un relleu català..., p. 29; ídem, Correr les armes..., p. 103; ídem, Círculo de Pere Joan..., p. 159.

153. Véanse los ejemplares reunidos desde el reinado de Pedro el Ceremonioso en el repertorio clásico de F. de SEgarra, Sigil-lografia Catalana, vol. I, Barcelona, 1916. En relación con el relieve de Poblet, hay ejemplares elocuentes del Ceremonioso, Juan I (como Infante y como rey), de Martín el Humano y de Alfonso. A favor de la mayor dependencia sigilográfica que del medallón de san Jorge de Pere Joan juega otro detalle: el hecho que el jinete situado en primer término lleve cimera sobre su bacinete, rasgo habitual en la imagen de los condes reyes a caballo que campea al dorso de sus sellos. El peso de la sigilografía en el relieve del Palau de la Generalitat de Pere Joan ya lo señaló: A. Duran y SANPERE, Els retaules..., vol. II, p. 33.

154. En el Museo de la Obra del monasterio se conserva un relieve de alabastro con unos jinetes, que podría proceder del panteón real y haber ilustrado precisamente esta ceremonia. Se trata de una realización de la segunda mitad del XIV adscribible al círculo de Jaume Cascalls. 
catalana a lo largo del siglo xiv, de los que podría no haber estado excluido el panteón real ${ }^{155}$.

Para el relieve, Pere Oller contaba con estos posibles precedentes trecentistas y con modelos sigilográficos contemporáneos en los que inspirarse. En cambio, sus plorantes, parecen acusar otro punto de partida: las figuras dolientes del escultor Antoni Canet. La dependencia de los pobletanos respecto a algunos del sarcófago del obispo Escales en la catedral de Barcelona es innegable (figura 11). Se ha copiado gesto y disposición corporal. Que sepamos, estos débitos de Pere Oller no han sido señalados hasta ahora, pero la confrontación con el mausoleo episcopal los hace evidentes. Puede descubrirse de este modo el modelo directo del plorante custodiado en Chicago, o el del dibujo de Milà i Fontanals, y también -invertidos respecto al original- el del perteneciente a la antigua colección Terez y el que posee el Metropolitan Museum.

Si el dibujo preparatorio del grabado de Laborde que hemos analizado con anterioridad ayuda a explicar la procedencia de parte de los plorantes pobletanos de Pere Oller y su función iconográfica: simular un cortejo fúnebre, el más verosimil de cuantos registramos en el arte gótico catalán y sin paralelos conocidos por el momento, no ocurre lo propio con los restantes elementos escultóricos que acusan también su estilo, por ejemplo el relieve del «correr les armes». En relación con este último, los restantes dibujos conservados son poco elocuentes, y no permiten un pronunciamiento categórico sobre cual era su emplazamiento exacto con anterioridad a 1836. Evidentemente, tras la intervención de Gil Morlanes a finales del siglo Xv en el túmulo del extremo occidental del arco sur, ya no había lugar para él en ese sitio. Hay que pensar, por tanto, que tras llevarse a cabo las remodelaciones de los túmulos del extremo occidental de los arcos, a finales del siglo xv, que suponemos, el relieve pudo desplazarse desde el del lado sur al del lado norte.

Es indudable que la presencia del cortejo fúnebre ejecutado por Oller en el arco contiguo a la sacristía, fuerza una interpretación de los hechos que, si bien tiene la ventaja de permitir encajar todos los datos conocidos, no deja de ser, como ya hemos dicho, bastante rocambolesca ${ }^{156}$. Entre otras cosas, hace que juzguemos la intervención de Gil Morlanes en el panteón pobletano a finales del siglo XV, mucho más trascendente de lo que se ha venido evaluando hasta ahora. En nuestra opinión, intervino en los dos mausoleos emplazados en el extremo occidental de los arcos, respetando en parte elementos antiguos - este cortejo fúnebre obra de Pere Oller, por ejemplo- pero labrando ex novo el frontal del mismo sepulcro contiguo a la iglesia y las estatuas yacentes ${ }^{157}$. Al sepulcro norte, destinado entonces a Fernando de Antequera, hubo que trasladar algunos elementos escultóricos del origi-

nario - entre ellos el relieve del «correr les armes»— puesto que, de no ser así, no se explicaría como habría llegado hasta el siglo XIX, pero desconocemos, y no nos atrevemos a especular al respecto, cómo se resolvió finalmente el mausoleo: si hubo que añadir piezas nuevas ${ }^{158}$, qué pudo pasar con lo que estaba destinado a sepulcro de Martín el Humano, etc. De lo que no hay duda, sin embargo, atendiendo a la noticia sobre la inhumación de Fernando de Antequera en su sepulcro definitivo el año 1432, es que, si hubo que enterrarlo de nuevo en 1499, fue porque entre ambas fechas ocurrió algo importante, y lo único que parece poder justificar tal cosa es la necesidad de acomodar un nuevo enterramiento sobre los arcos reales para el que no había sitio, salvo que se hurtara el destinado a Martín el Humano. Tal hecho suponía dejar para siempre fuera de ese espacio privilegiado el cadáver de éste último y trasladar a un lugar distinto del primitivo el de Fernando de Antequera, como creemos que ocurrió. Juan II tuvo de este modo un lugar en la genealogía real póstuma que había concebido Pedro el Ceremonioso, más de cien años antes, al ordenar la construcción de los arcos sepulcrales de Poblet.

155. El testimonio más antiguo conocido es el que hubo en el sepulcro del conde de Urgell, Ermengol X, en el convento premostratense de Les Avellanes, de donde pudo irradiar al área leridana, que es donde se concentra el mayor número de ejemplos a lo largo del siglo XIV. Reaparece en el sepulcro dinástico de los Montcada en la capilla de san Pedro de la catedral de Lleida y en el que una línea colateral en el cercano monasterio de Avinganya cuyas características no son conocidas por descripciones antiguas, dado que esta parte del sepulcro se ha perdido. Lo descubrimos de nuevo en el sepulcro de los Queralt en Santa Coloma (Tarragona), obra, en parte, de un artífice leridano. Reaparece por tierras valencianas en una realización vinculada a un escultor leridano: el sepulcro de los Boil en Santo Domingo de Valencia que hemos adscrito a Bartomeu de Robio. Al respecto de este tema iconográfico, lamentamos el comentario que nos dedica M.R. Manote, Correr les armes..., p. 117 , nota 76 , que evidencia su desconocimiento de distintos tra- bajos publicados por nosotros entre 1984 y 1995 (se referencian todos en: F. EsPañol, «Els comtes d'Urgell i el seu panteó dinàstic», en: El Comtat d'Urgell, Lleida, 1995, p. 176, notas 546 y 547, p. 168 , nota 536), así como del contenido de nuestra tesis doctoral (véase la nota 25), en la que reunimos por primera vez la serie de testimonios enumerados más arriba que constituyen el primer corpus sobre el tema. También, que una vez consultados esos estudios con posterioridad, utilice la información que proporcionan, sin citar ninguno de ellos (cf. M.R. Manote, Círculo de Pere Joan..., p. 160, nota 2).

156. La interpretación puede parecerlo, pero no lo es menos la historia del panteón real a lo largo del reinado del Ceremonioso: modificaciones sucesivas del proyecto original, cambios de ubicación de los sepulcros, reaprovechamiento de figuras yacentes talladas inicialmente para el sepulcro de unos monarcas y destinadas finalmente al de otros. Para esta sorprendente peripecia de uno de los proyectos más emblemáticos de la monarquía: A. Altisent, Història..., p. 261-296.

157. Aunque a lo largo de los párrafos que hemos dedicado a Morlanes siempre hemos personalizado la obra del panteón real en él, hay que recordar la importancia del taller en la producción del artífice, y, especialmente, el pacto de colaboración firmado en las proximidades de su incorporación a la obra del panteón real de Poblet, entre Gil Morlans y Pedro de Amberes, o con "maestre Anrich» imaginero de Logroño. Sobre los términos del primer contrato, véase: M. SERRANO SANZ, op. cit., para los del segundo, C. Morte, Fernando el Católico..., p.161, 189-190, doc. 10.

158. Esta posibilidad permitiría explicar la razón de ser de los relieves de alabastro de finales del siglo $\mathrm{xV}$, de escasa calidad, existentes en Poblet, que en algún caso aparecen reinsertados, sorprendentemente, en el frontal del mausoleo de Juan II y Juana Enríquez. Véase lo apuntado al respecto de esta cuestión en la nota 146 . 